Part of Journal of Research of the National Bureau of Standards, Volume 19, December 1937

\title{
DIMENSIONAL CHANGES IN AERIAL PHOTOGRAPHIC FILMS AND PAPERS
}

By Raymond Davis and Emory J. Stovall, Jr.

\section{ABSTRACT}

Results of a study of dimensional changes in aeromapping photographic film and papers under controlled conditions are presented. Both films and papers are subject to a shrinkage from processing. These materials are hygroscopic, consequently their dimensions change with the varying moisture content of the air. Dimensional changes from both processing and moisture content are least in the machine direction, that is, along the roll. Films continue to shrink with time, because of a loss of solvents and plasticizer. This shrinkage is illustrated by accelerated-aging tests at $120^{\circ} \mathrm{F}$ covering a period of 32 days. Two new instruments developed for measuring film shrinkage are described. A reduction of differential shrinkage in the final print or duplicate negative can be had by crossing the machine directions of the negative and printing material during exposure.

CONTENTS

Page

I. Introduction .

II. Materials

III. Apparatus and methods for measuring shrinkage

IV. Reproducibility of the measurements

V. Film shrinkage as a function of conditioning time

VI. Film shrinkage as a function of accelerated-aging time

VII. Shrinkage of aerofilms as a function of relative humidity

VIII. Film shrinkage due to processing and accelerated aging

IX. Shrinkage of photographic papers caused by processing .

$\mathrm{X}$. Summary and recommendations

\section{INTRODUCTION}

Photographic films and papers are not stable with respect to their dimensional characteristics. It is well known that these materials not only change their dimensions with a change in moisture content, which tends to follow similar changes in the atmosphere, but are subject to shrinkage caused by the process of developing, fixing, and washing. For aeromapping the dimensional change is not serious if uniform in all directions and its magnitude known, as a change of scale is all that would be needed for correction. The actual case is complicated by the fact that both papers and films shrink more in one direction than in the other. Both paper and celluloid are manufactured by a continuous process, the product being in the form of a long ribbon. The greatest shrinkage is always in the crosswise direction.

While these facts have been known for a long time, only meager and incomplete data on the magnitude of the effects of moisture and processing under controlled conditions have been available. During the last few years, aerial surveying has been undertaken on a large 
scale, and the need for information on the dimensional changes in films and papers has become acute. For work in which high accuracy is desired, considerable difficulty has been encountered in obtaining film and paper with satisfactory shrinkage characteristics. The better aerial cameras are fitted with lenses selected for minimum distortion. The magnitude of the distortion for these lenses is of the order of $0.04 \mathrm{~mm}$ at the edge of a $22.9-$ by $22.9-\mathrm{cm}$ ( 9 in. by $9 \mathrm{in}$.) plate. This value amounts to 0.035 percent. In films distortion is measured by the difference in shrinkage, expressed as a percentage, in the two directions and is called "differential shrinkage." The differential shrinkage in films should not exceed the distortion of the lenses, that is, 0.035 percent.

\section{MATERIALS}

The American Society of Photogrammetry, through its President, Col. H. H. Blee, secured the film and paper samples from photographic manufacturers, governmental agencies, and privately operated aerosurveying services. The film and paper samples tested are representative of those in current use for aeromapping with the exception of two samples of cut film, one of which was experimental. From two to eight samples of each brand of film were tested, each sample being from a different lot of the same trade name. The different samples of the same brand are grouped together in the tables. From these groups an idea of the uniformity of the product can be had. In all, 24 separate lots of film were tested and, with the exception of two samples, all were on nitrate base.

Most of the papers submitted were regular photographic papers-in all, there were 57 items of which only 8 were marked "special low shrink" or " aeromapping papers."

\section{APPARATUS AND METHODS FOR MEASURING SHRINKAGE}

Apparatus suitable for measuring film shrinkage may be of two general types - optical or mechanical. The optical devices generally used consist of either a micrometer microscope actuated by a calibrated screw, such as used for measuring line-spectrum negatives, or the comparator type of instrument with which a length standard is compared by two micrometer microscopes with reference marks on the film.

The use of devices employing microscopes is both slow and laborious, each an important factor in a large number of measurements. Rapid and convenient means of measuring film shrinkage not being available, two different instruments were designed and constructed for this work, one a rapid and accurate mechanical gage or extensometer for measuring films, and the other an optical extensometer suitable for both paper and films.

The use of this mechanical extensometer, referred to throughout this report as "pin gage", does not necessitate the use of a darkroom as no developed image is used in the measurements.

The procedure with the pin gage is as follows: Strips 2 inches wide and 10 inches long are cut from the film for lengthwise samples. Crosswise samples are cut to the same width but to a length $9 \frac{1}{2}$ inches, 
which is the full width of the $24-\mathrm{cm}$ aerofilm. The difference in length serves to distinguish the lengthwise samples from the crosswise samples. However, each individual test strip is also given an identifying number. After the samples are cut, which may be done in a lighted room, they are numbered and hung up by wooden photoclips in the conditioning room for the prescribed time. Two pairs of holes $1 / 4$ inch in diameter and 8 inches apart are then punched in the film (see fig. 1). The holes may be 5 inches apart for use with a 5 -inch gage in the case of narrow film.

The punched film is measured on the pin gage and the readings recorded. The samples are then developed, fixed, washed and dried, and returned to the conditioning room. After reconditioning for the prescribed time, they are again measured with the pin gage. The difference between the pin-gage readings before and after developing the film gives the dimensional change due to processing.

The 8 -inch pin gage, removed from its case, is illustrated in figure 2. $A$ and $B$ are steel pins $1 / 4$ inch in diameter and have rounded ends. Pin $A$ is fixed to the heavy-steel face plate $C$ at a distance of $7 \frac{3 \pi}{4}$ inches from pin $B$, the outside measure being 8 inches. Pin $B$ passes through a slot in the face plate and is fastened to a suspension bridge $D$ immediately below. The bridge supporting this movable pin $B$ is suspended from the underside of the face plate by two spring-steel flexure plates $E, 0.005$ inch thick, one at each end, which permit the bridge supporting the movable pin to move toward and away from the fixed pin a total distance of approximately 0.1 inch. A dial gage $F$ fastened to the underside of the face plate is connected to the suspension bridge at the point $G$ by a metal rod $H$. The face plate and bridge are made of steel, and the rod $H$ is of duralumin of such a length that it compensates for any changes of temperature. For the work reported here, temperature compensation was unnecessary; but the correction was so simple to make that this feature was incorporated in the design. A coil spring (not shown in fig. 2) fastened to the face plate and suspension bridge maintains tension of about 75 grams on the sample placed over the pins. The holes in the film were made with a punch (fig. 3) designed for the purpose. The lever bar and punch pins were from a commercial paper punch. The punch was machined to specified dimensions, and hardened-steel dies made to fit were imbedded in the steel base plate. This punch makes clean holes for either the 5 -inch or 8-inch gage lengths. A metal plate (not shown) may be used to keep the film flat during the punching operation. Since the film is measured after punching and before processing, high accuracy in the spacing of the holes is unnecessary. However, if care is taken excellent reproducibility can be obtained.

Ordinarily, 30 test strips were cut from each roll of aerofilm tested, 15 cut crosswise and 15 lengthwise. One group of strips, five in each direction, was left unprocessed in the conditioning room as a control. The processed samples were first conditioned as mentioned, developed for 3 minutes in trays of metol-hydroquinone developer, rinsed in a dilute acetic acid short-stop bath, fixed 12 to 15 minutes in an acid fixing bath, washed 30 to 60 minutes in running water, and hung up to dry in the uncontrolled atmosphere of the laboratory. The dried samples were returned to the conditioning room, conditioned for the prescribed time, and remeasured along with the control strips to deter- 
mine the shrinkage due to processing. A third group of film strips, cut, punched, processed, and measured, as explained above, were put in a paper envelope (to prevent excessive curling) and placed in an oven maintained at $120^{\circ} \mathrm{F}\left(49^{\circ} \mathrm{C}\right)$, usually for 7 days, then taken back into the conditioning room to be reconditioned and measured.

Excellent results on film were obtained with the pin gage, but with photographic papers this procedure was not satisfactory. Paper is not sufficiently flexible nor does it have the mechanical strength or wear resistance to give good reproducibility. Using the mechanical principles of the pin gage, an optical extensometer was designed for measuring paper shrinkage. This instrument is shown in figure 4. The box contains a mechanism similar to the pin gage, but the two pins are replaced by two $32-\mathrm{mm}$ Micro-Tessar objectives, one movable and the other fixed. These lenses are in fixed focus on the upper surface of the plate-glass top of the instrument. The glass is painted black on the underside except for two rectangular patches immediately above the objectives. By means of prisms the beams from the lenses

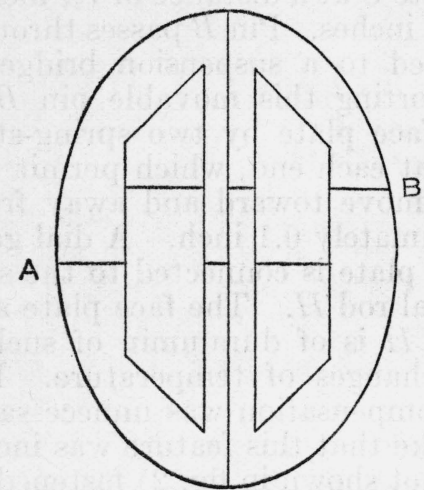

Figure 5.-Pattern observed in the eyepiece of the optical gage.

$A$ is imaged by the fixed objective, $B$ by the movable objective.

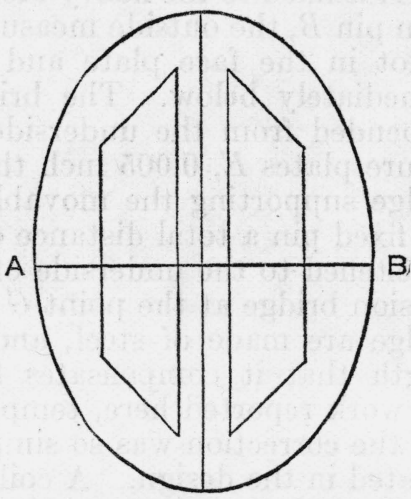

Figure 6.-Pattern observed in the eyepiece of the optical gage.

$A$ is imaged by the fixed objective, $B$ by the movable objective.

are brought to a focus on a Lummer-Brodhun photometric cube, which brings the separate images into juxtaposition. A brass tube fitted with a lens and hard-rubber cap with a small hole constitutes the eyepiece of the instrument; this is focused on the photometric cube. On the end of the box to the right a micrometer is fitted to move the lens and measure its displacement. On the other end of the box is a dial gage, which also indicates the position of the lens. Either micrometer or dial gage may be read; however, while slightly less accurate than the micrometer, the dial gage is preferable because of ease of reading. The gage length (distance between lenses) of this instrument is 6 inches. The following illustrates the operation of the instrument: if a print on paper or film having a pair of parallel lines spaced 6 inches apart is placed face down on the glass top of the instrument so that the lines are in the field of view of the lenses one would see in the eyepiece a pattern as shown in figure 5. In figure 5 line $A$ is produced by the fixed lens and line $B$ is from the movable lens. If the micrometer screw is turned in the proper direction line $B$ 


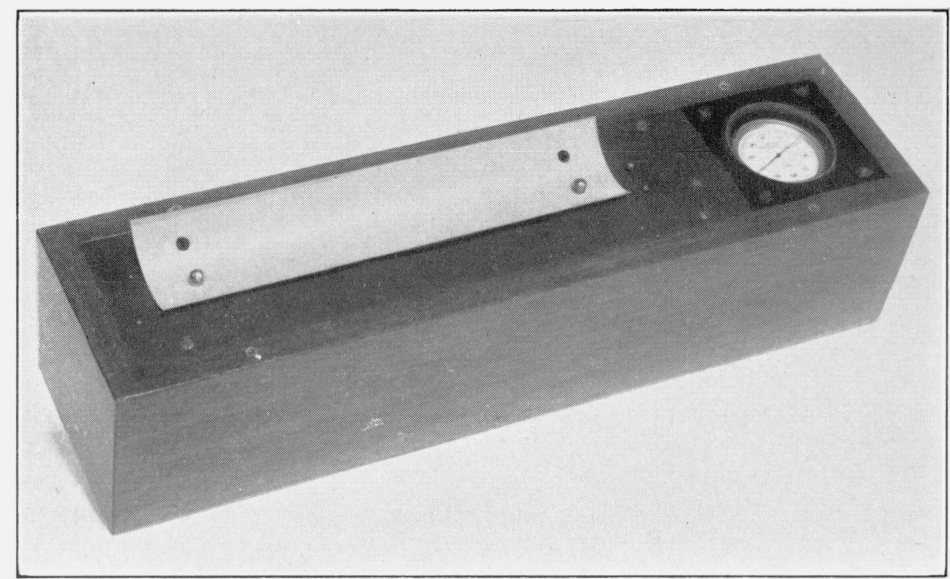

Figure 1.-Pin gage, with strip of film in place for measurement.

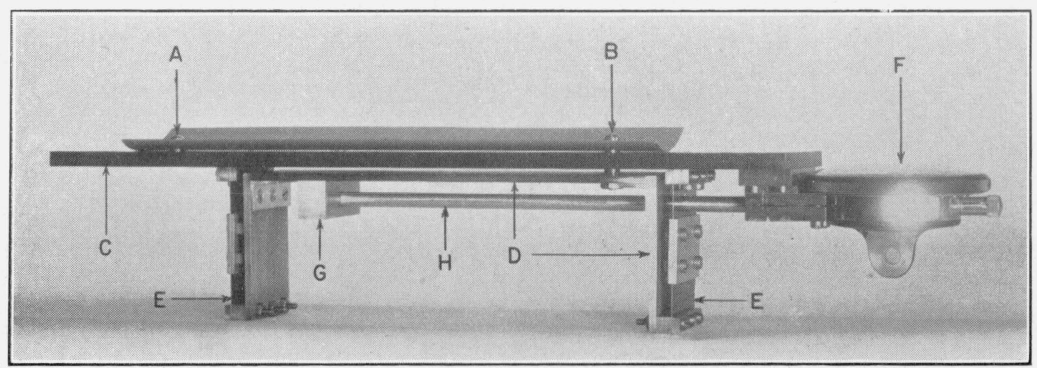

Figure 2.-Pin gage removed from its case.

$A-$ Fixed pin.

$B$-Movable pin.

$C$-Face plate.

$$
\begin{aligned}
& D \text {-Suspension bridge. } \\
& E \text { - Flexure plate. } \\
& F \text {-Dial gage. }
\end{aligned}
$$

G-Anchor block for $H$.

$H$-Duralumin rod for temperature compensation. 


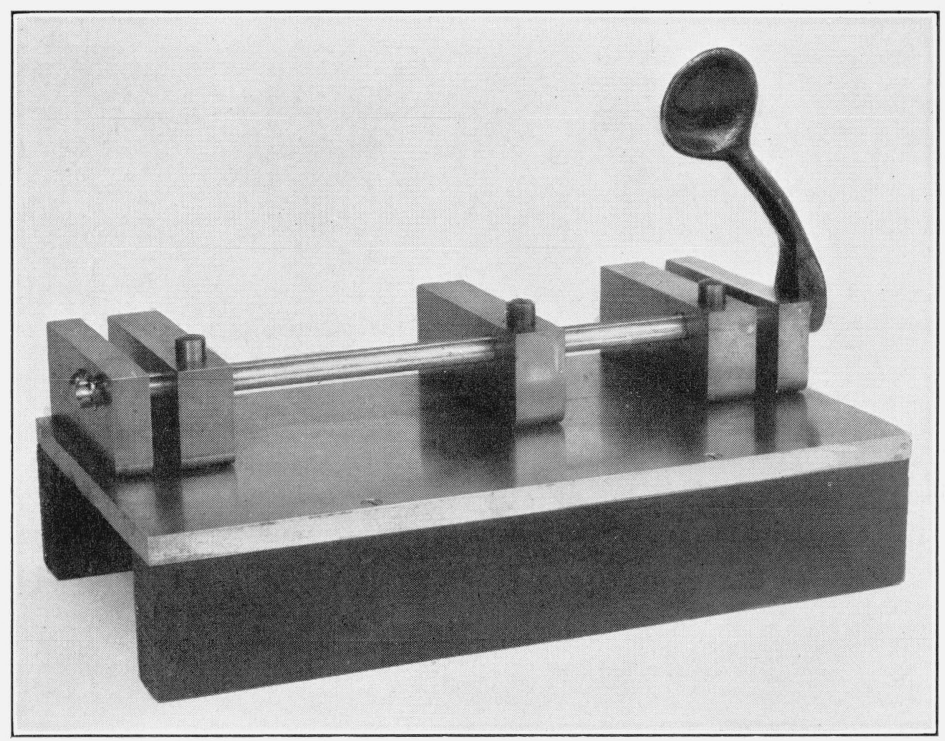

FIGURE 3.-Punch used for making reference holes in films, either 5 or 8 inches apart.

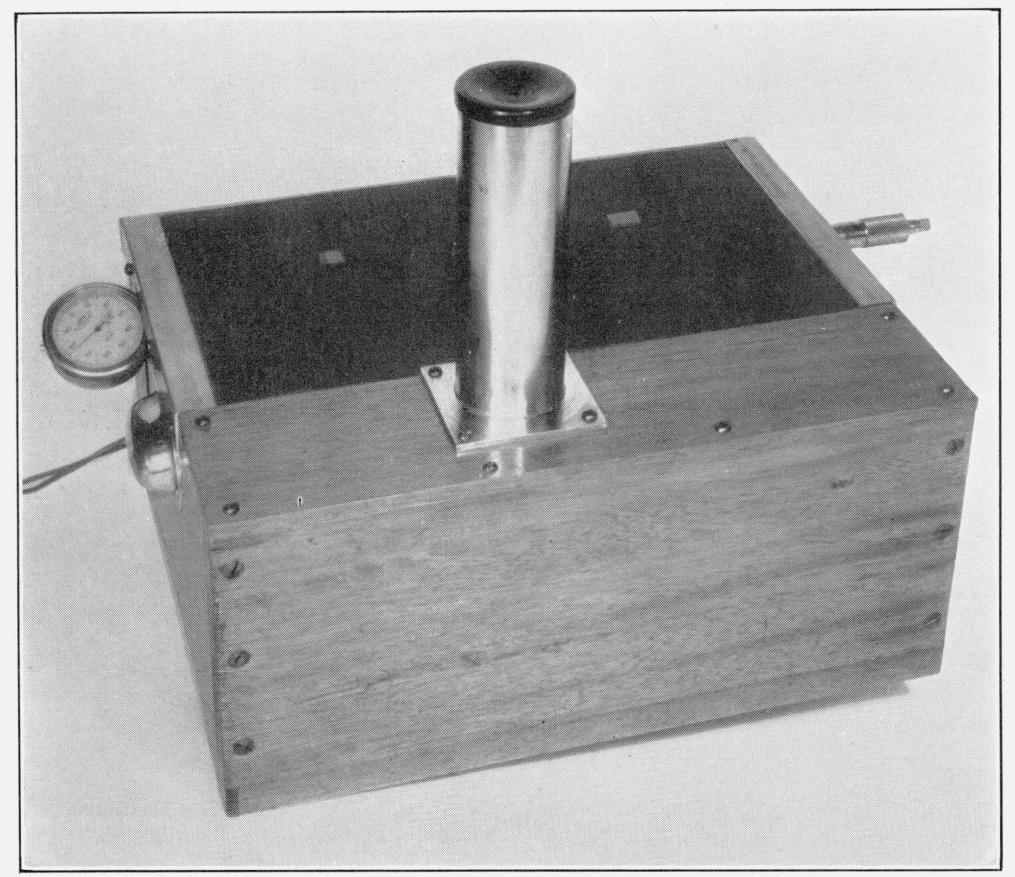

Figure 4. - Ortical gage. 
will be moved into coincidence with line $A$, as shown in figure 6 . The magnification is 10 diameters. The obvious advantage of this instrument, in which both fields are seen in a single eyepiece, over the usual comparators is that a single setting is sufficient. Comparators ordinarily require separate settings on two reference lines. Matching ends of lines, as in the present instrument, is more accurate than centering a line between two parallel hairs or centering on cross hairs in two observing microscopes for a single measurement.

To determine the shrinkage of photographic paper or film with this optical gage, the sample, after conditioning in the dark, is exposed in the conditioning room under a negative of a Max Levy ruled-glass grid consisting of fine lines spaced $3 / 2$ inch, as shown in figure 7 . After developing, fixing, and washing and drying, the sample is reconditioned for a prescribed interval of time and then measured. In the measuring operation, the first step is to measure a similar reference print of this grid made on a photographic plate, in six different positions, three lengthwise and three crosswise. With the fixed dimensions of the

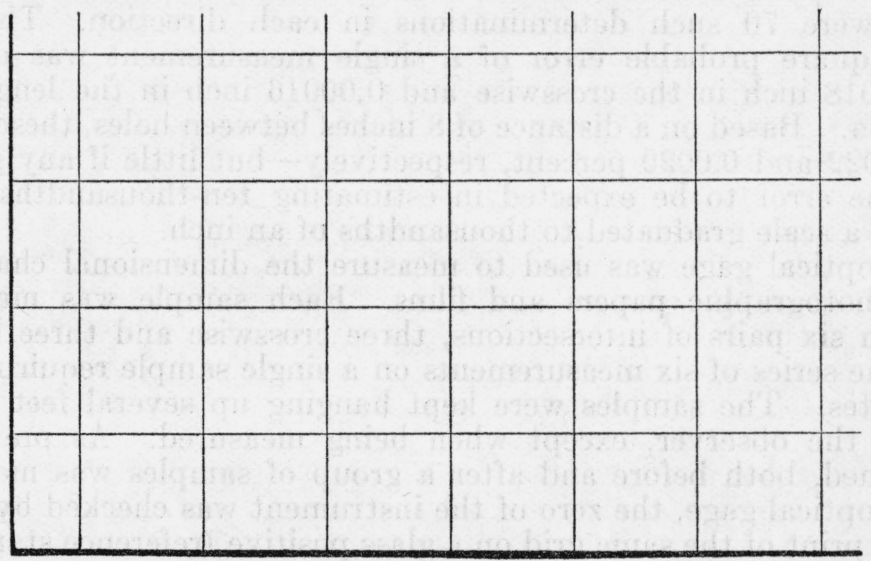

FIGURE 7.-Section of a photograph of the ruled-glass grid, full size, to show character of ruling.

plate as standard the separations of six pairs of points on the sample are compared with those of the same pairs of points on the grid. After measurement of the paper or the film has been completed the standard plate is again measured to check the zero of the instrument.

\section{REPRODUCIBILITY OF THE MEASUREMENTS}

Careful handling of the film is necessary to obtain accurate readings with the pin gage and to avoid damage to the film. The manner of placing the film on the pins and removing it is important. The strip with the emulsion side up should be grasped at the ends between fingers and thumbs, held under tension, and slipped over both pins simultaneously. The strip is then pushed into contact with the top plate of the gage, the thumbnails pressing lightly on the outside of the pins. The instrument is then tapped lightly with the finger or a pencil so as to eliminate friction or sticking in the dial gage. The dial gage, graduated to thousandths of an inch, is read to ten thousandths of an inch. The strip is removed from the instrument by 
grasping the ends as before and holding it under tension while lifting it off the two pins simultaneously. These operations consume only about 10 seconds.

The strips are kept hanging up several feet away from the observer except during the actual operations of measurement, so that the effect of moisture from the observer's breath and body on their dimensions will be small. The zero of the pin gage should be checked each time a series of measurements is made by noting the readings on the dial gage when the movable pin is displaced to its imposed limits. In the present study, these readings never vary by more than 0.0002 inch, so no zero-correction was ever found necessary.

To test the reproducibility of measurements made on the pin gage, 10 strips of film, 5 cut crosswise and 5 lengthwise, were conditioned, two pairs of holes punched in each, and measured. They were then kept in the conditioning room (unprocessed) and remeasured seven times during a period of 8 days. The deviation of the change in spacing from the initial measurement from the average change between 10 pairs of holes measured at the same time was recorded. There were 70 such determinations in each direction. The root mean square probable error of a single measurement was derived as 0.00018 inch in the crosswise and 0.00016 inch in the lengthwise direction. Based on a distance of 8 inches between holes, these errors are 0.0022 and 0.0020 percent, respectively - but little if any greater than the error to be expected in estimating ten-thousandths of an inch on a scale graduated to thousandths of an inch.

The optical gage was used to measure the dimensional change of both photographic papers and films. Each sample was measured between six pairs of intersections, three crosswise and three lengthwise, the series of six measurements on a single sample requiring 2 or 3 minutes. The samples were kept hanging up several feet to one side of the observer, except when being measured. As previously mentioned, both before and after a group of samples was measured on the optical gage, the zero of the instrument was checked by measuring a print of the same grid on a glass positive (reference standard). From the deviations of the individual pairs of measurements on the reference standard, the probable error of a single measurement on the instrument was computed. Based on 20 sets of measurements of the plate, 240 individual measurements, the probable error here was 0.00009 inch, or 0.0015 percent of the 6 -inch gage length. As with the pin gage, this error is not greater than the error to be expected in estimating ten-thousandths on a scale graduated to thousandths of an inch.

The probable errors of both instruments are about 0.002 percent. The dimensions of the films are not nearly so reproducible when the surrounding conditions are changed. A group of 10 strips of film were hung on a line for 24 hours in the conditioning room, measured, and rehung. A 40-watt lamp was placed at a distance varying from 1 to 3 feet from the film samples and kept burning for several hours. The lamp was removed, and after a period of 24 hours the films were again measured. The probable fluctuations of the measurements were then 0.004 percent crosswise and 0.008 percent lengthwise in 8 inches, from 2 to 4 times the probable error of the gages. The prob- 
able fluctuation of the measured dimensional change of a strip of film, due to accelerated aging $\left(120^{\circ} \mathrm{F}\right.$ for 7 days), was computed for several groups of strips of film and was found to be about 0.02 to 0.04 percent. This is about 10 to 20 times the error of the instruments.

The measurements used in computing the probable errors of the gages were made by an experienced observer, who has made several thousand measurements on each of the two instruments, and hence has acquired a technique for handling the strips rapidly and precisely. Precautions were taken to eliminate as much as possible the effect of heat from the lamp and of moisture from the observer's body and breath on the samples of film. If these precautions are not taken the fluctuations will, of course, be larger.

\section{FILM SHRINKAGE AS A FUNCTION OF CONDITIONING TIME.}

It is well known that photographic film changes in dimension with change in moisture content, and that the amount of moisture in the

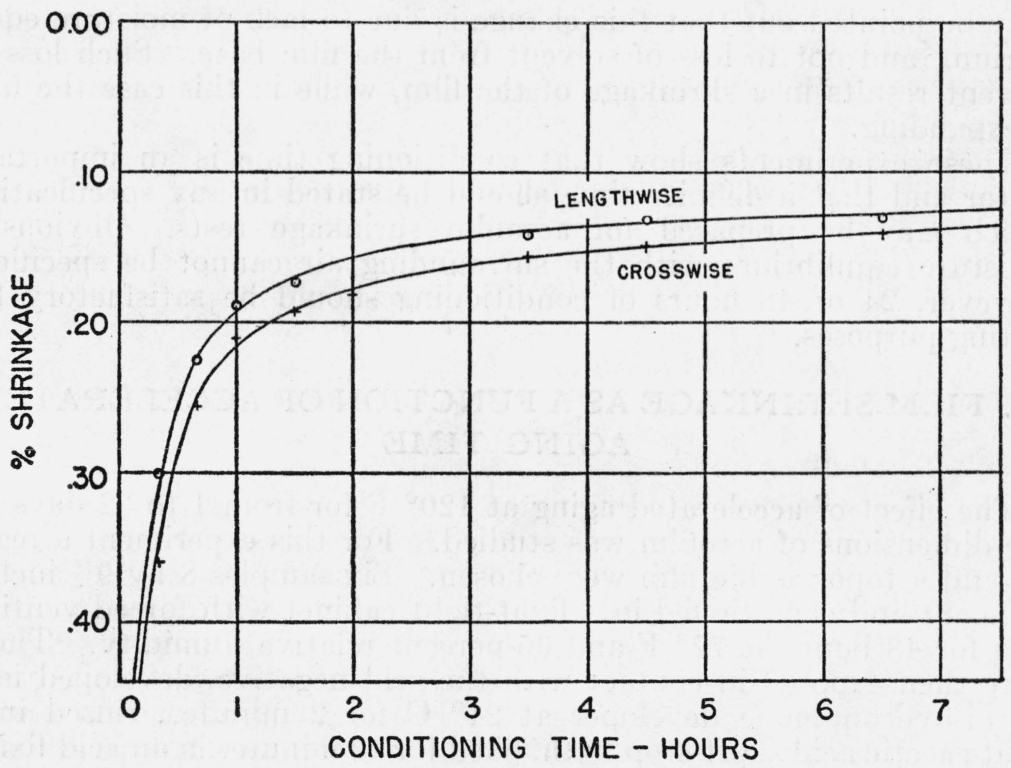

FIGURE 8.-Graph showing percentage of shrinkage as a function of conditioning time for special aerofilm.

film tends to follow a change in the atmosphere. However, no information on the time required for film to reach equilibrium was available.

The rate of approach to dimensional equilibrium with humidity was investigated for three different films: A regular, a topographic, and a special low-skrinkage film. These films were in rolls $9 \frac{1}{2}$ inches wide and 25 feet long. Test strips of these were conditioned at 65 percent relative humidity and processed. When each strip was thoroughly dry it was put in a paper envelope and kept in an oven at $120^{\circ} \mathrm{F}$ for 24 hours, and then put in an open can and returned to the 
oven for an additional 24 hours. At the end of this period the can was covered, sealed with tape, and transferred to the conditioning room, where the can was opened and the film strips measured immediately and the time noted. While the moisture in the film was coming to equilibrium with the air in the conditioning room, a series of measurements were made, extending over a period of 16 days. From these measurements was computed the dimensional change of the films, based on their original measurement before processing.

The results for the topographic film, shown in figure 8, were plotted on a linear scale as a percentage dimensional change against time up to about 7 hours. These curves, rising steeply for 1 or 2 hours and then leveling off, seem to indicate that equilibrium is approximately reached within a few hours. However, this is not strictly true. The results from all three films, shown in figures 9,10 , and 11, were plotted as percentage dimensional change against the logarithm of the conditioning time, up to 16 days. These curves show that dimensional equilibrium was not reached even after 2 weeks of conditioning, and that about 100 days would be required to establish equilibrium. It may be pointed out that this change is due to lack of moisture equilibrium, and not to loss of solvent from the film base. Such loss of solvent results in a shrinkage of the film, while in this case the film is expanding.

These experiments show that conditioning time is an important factor and that a definite time should be stated in any specification which may be prepared for aerofilm shrinkage tests. Obviously, moisture equilibrium with the surrounding air cannot be specified; however, 24 or 48 hours of conditioning should be satisfactory for testing purposes.

\section{FILM SHRINKAGE AS A FUNCTION OF ACCELERATED- AGING TIME}

The effect of accelerated aging at $120^{\circ} \mathrm{F}$ for from 1 to 32 days on the dimensions of aerofilm was studied. For this experiment a regular and a topographic film were chosen. Six samples 8 by $9 \frac{1}{2}$ inches were cut and conditioned in a light-tight cabinet with forced ventilation for 48 hours at $72^{\circ} \mathrm{F}$ and 65 -percent relative humidity. These were then exposed in contact with the grid negative, developed in a metol-hydroquinone developer at $21^{\circ} \mathrm{C}$ for 2 minutes, rinsed in a dilute acetic acid short-stop bath, fixed for 12 minutes in an acid fixing bath, washed 30 minutes in running water, and then dried overnight in the laboratory. After reconditioning for 48 hours at $72^{\circ} \mathrm{F}$ and 65 -percent relative humidity, the samples were measured on the optical gage. After measuring each film it was put in a paper envelope and placed in an oven maintained at $120^{\circ} \mathrm{F}\left(49^{\circ} \mathrm{C}\right)$. One sample from each roll was removed after $1,2,4,9,16$, and 32 days, respectively. The samples were then reconditioned at $72^{\circ} \mathrm{F}$ and 65 -percent relative humidity for 48 hours and again measured on the optical gage.

The shrinkage of the films due to accelerated aging was computed from the difference in the dimensions of the film after processing and after oven treatment. The results in figure 12 were plotted with percentage shrinkage as ordinates and the logarithm of the time in the oven in days as abscissas. It will be noted that the points lie approxi- 


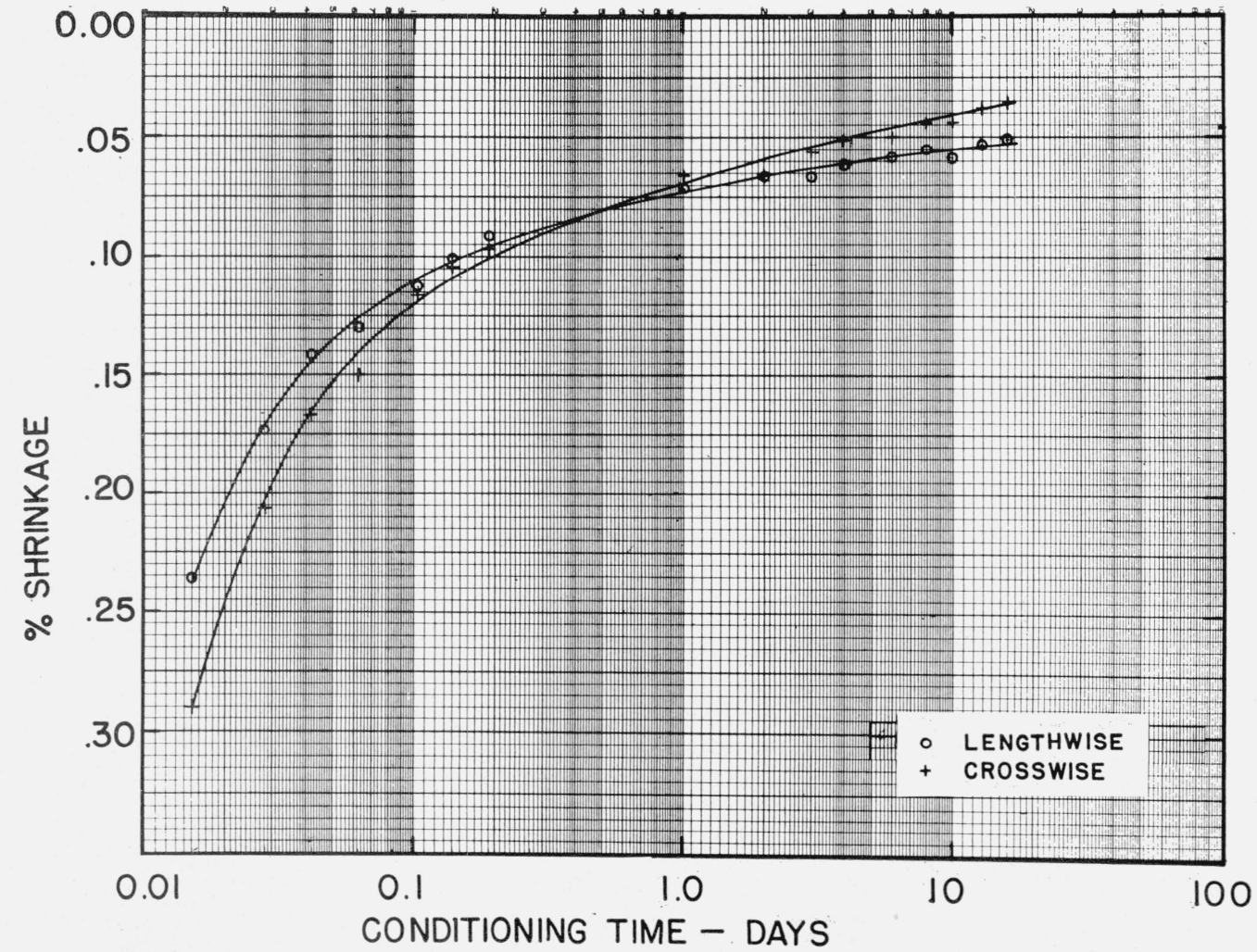

FIGURE 9.-Graph showing percentage of shrinkage as a function of the logarithm of conditioning time for topographic film. 


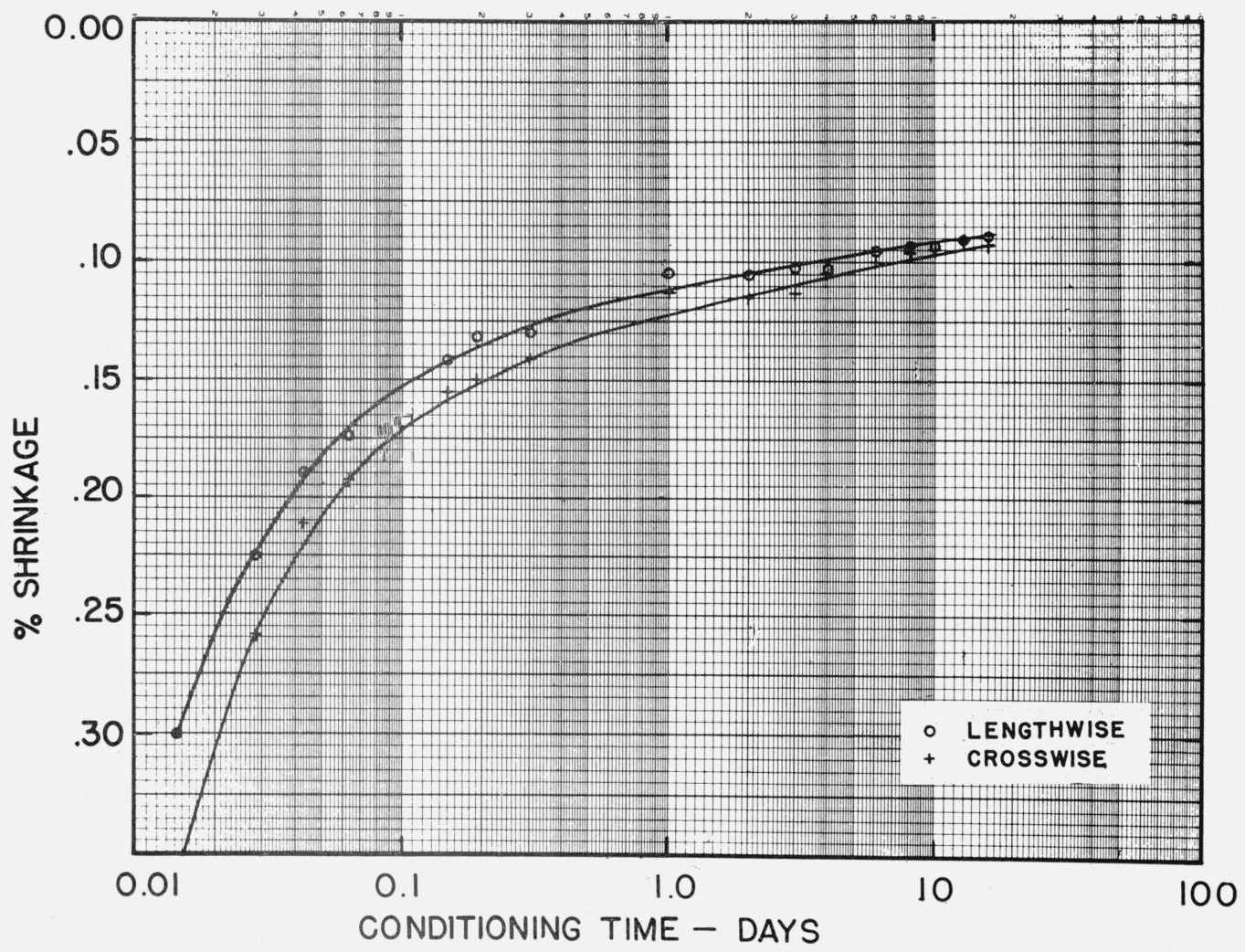

FIGURE 10.-Graph showing percentage of shrinkage as a function of the logarithm of conditioning time for special aerofilm. 


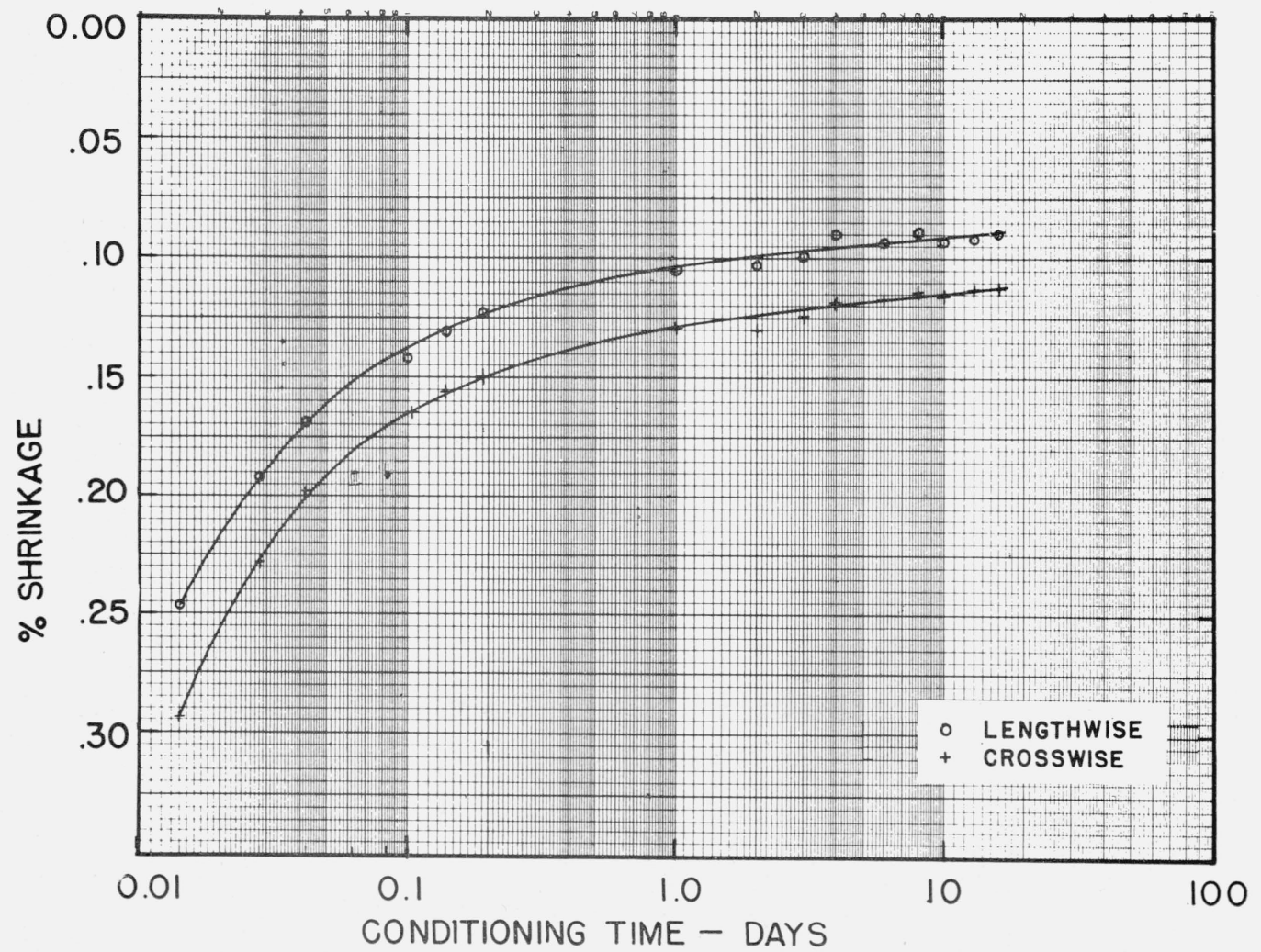

FIGURE 11.-Graph showing percentage of shrinkage as a function of the logarithm of conditioning time for regular aerofilm. 
mately on a straight line. The shrinkage is seen to be greater in the crosswise direction, and the rate of shrinkage is greater in the crosswise direction, for both films. The shrinkage of the regular film is much greater than that of the topographic film and also its rate of shrinkage is slightly greater.

The position of the lines through the points in figure 12 was obtained by least squares. The same data, plotted on a linear time scale, are shown in figure 13. The solid lines in this figure are trans-

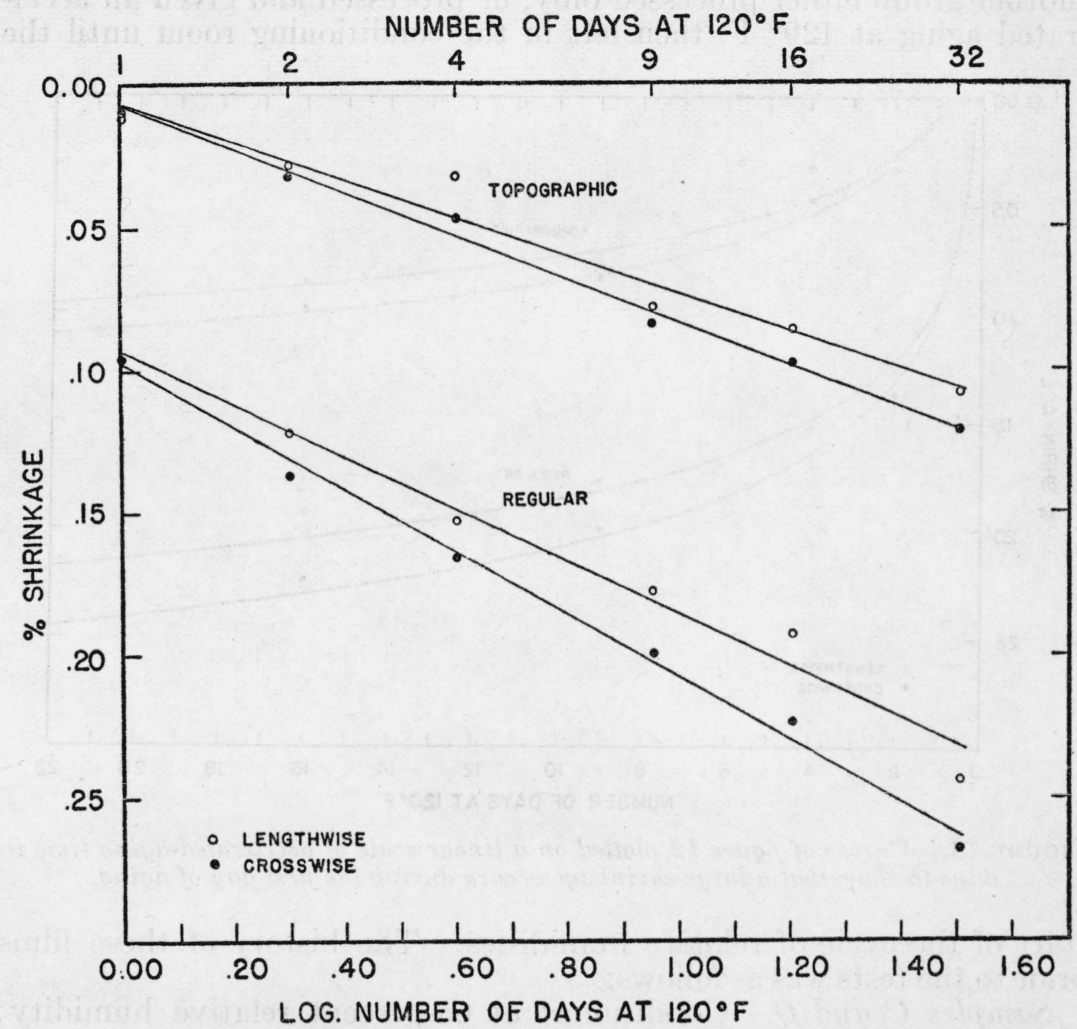

FIGURE 12.-Linear relationship between percentage of shrinkage and the logarithm of the time in days of accelerated aging for regular-and topographic-base films.

formed from the straight lines in figure 12. The dashed portions of the curves are estimates of the behavior of the films in the oven for less than 1 day, and, of course, this may not be exact.

\section{SHRINKAGE OF AEROFILMS AS A FUNCTION OF RELATIVE HUMIDITY}

In connection with a separate project, the conditioning room ordinarily maintained at 50-percent relative humidity was to be operated at a series of relative humidities. The program called for periods of approximately a week's duration at $32,43,65,76,86,65$, 
and 50-percent relative humidity, the temperature to be kept constant at $72^{\circ} \mathrm{C}$.

Advantage was taken of this schedule to determine the film shrinkage under these conditions. Seventeen samples of aerofilms representing six different brands of films were studied. Some of these samples had already been used for other purposes and consequently had been cut, conditioned, and measured some time previously. In each case, one group of test strips was left in the conditioning room unprocessed and another group either processed only, or processed and given an accelerated aging at $120^{\circ} \mathrm{F}$, then left in the conditioning room until the

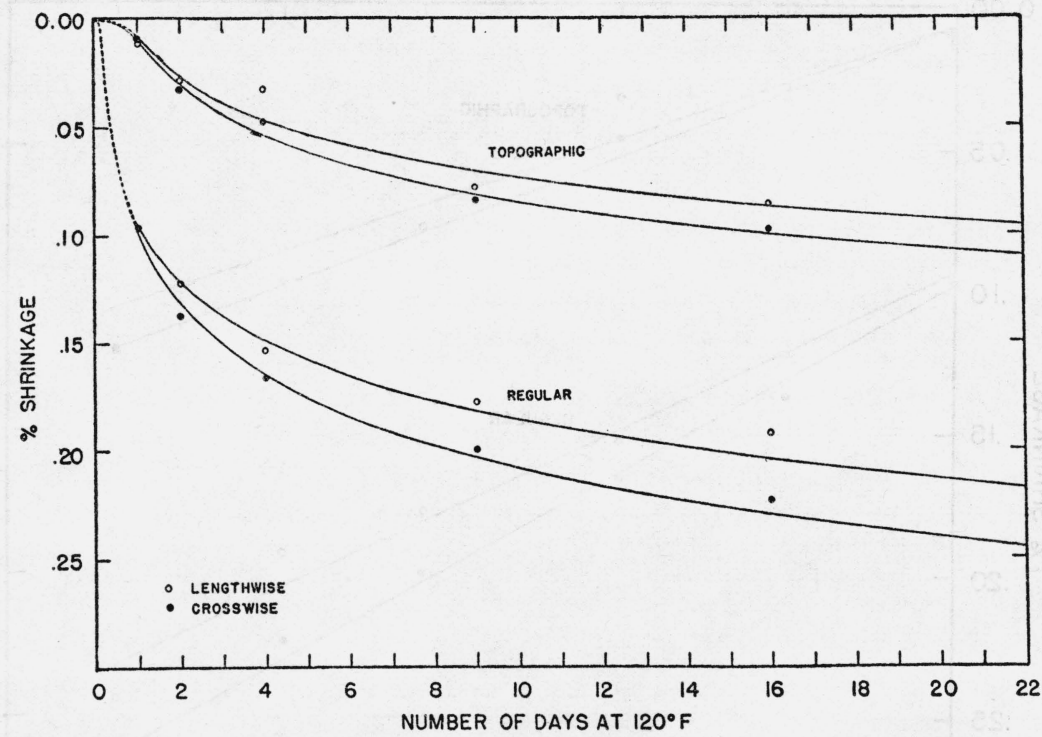

FIGURE 13.-Curves of figure 12 plotted on a linear scale of accelerated-aging time in days to show that a large shrinkage occurs during the first day of aging.

start of the cycle of relative humidities. The history of these films prior to the tests was as follows:

Samples $C$ and Q.-Conditioned at 65-percent relative humidity; unprocessed films were conditioned for 53 days; films oven-treated for 7 days were reconditioned for 42 days; films oven-treated for 14 days were reconditioned for 35 days.

Sample F.-Conditioned at 50-percent relative humidity; unprocessed films were conditioned for 22 days; and films oven-treated for 7 days were reconditioned for 11 days.

Sample G.-Conditioned at 50-percent relative humidity; unprocessed films were conditioned for 19 days; and films oven-treated for 7 days were reconditioned for 9 days.

Sample I.-Conditioned at 50-percent relative humidity; unprocessed films were conditioned for 11 days; and films oven-treated for 7 days were reconditioned for 2 days. 
Sample J.-Unprocessed films were conditioned for 8 days at 50percent relative humidity; and films oven-treated for 7 days were started in the cycle of humidities at 32 percent immediately after removing from oven.

Sample 0.-Conditioned at 50-percent relative humidity; unprocessed films were conditioned for 24 days; films oven-treated for 7 days were reconditioned for 15 days.

Samples $A, B, C, H, K, N, P, Q, R, S, T$, and $U$.-Conditioned at 50-percent relative humidity; unprocessed films were conditioned for 3 days; and processed films were reconditioned for 2 days.

After receiving the treatments indicated, all films were conditioned at the following relative humidities before being measured:

3 days at 32 percent, 4 days at 43 percent, 7 days at 50 percent, 10 days at 65 percent, 7 days at 76 percent, 5 days at 86 percent, 7 days at 65 percent, and 7 days at 50 percent. Immediately before the conditions in the room were changed to a new humidity, the film samples were placed in sealed cans, where they remained until the new humidity condition had been established.

The dimensional changes of the films were computed and tabulated as change from the original measurements made on the films at 50- or 65 -percent relative humidities. The results are given in table 1. Each value in the table is the average of 10 measurements on the film. The results on six of these films were plotted in figures 14 to 19 as percentage dimensional change against relative humidity. Unprocessed films are shown by full lines; films only processed, by dashed lines; and film processed and oven-treated, by dotted lines.

TABLE 1.-Dimensional change of films in percentages as a function of relative humidity

\begin{tabular}{l|c|c|c|c|c|c|c|c}
\hline & \multicolumn{7}{|c}{ RELATIVE HUMIDITY } \\
$\begin{array}{l}\text { Treatment and direc- } \\
\text { tion of measurement }\end{array}$ & $32 \%$ & $43 \%$ & $50 \%$ & $65 \%$ & $76 \%$ & $86 \%$ & $65 \%$ & $50 \%$ \\
\hline
\end{tabular}

REGULAR FILM BASE-SS. PANCHROMATIC-SAMPLE $A$

\begin{tabular}{|c|c|c|c|c|c|c|c|c|}
\hline $\begin{array}{l}\text { Unprocessed: } \\
\text { Crosswise } \\
\text { Lengthwise }\end{array}$ & $\begin{array}{r}-0.144 \\
-.132\end{array}$ & $\begin{array}{r}-0.089 \\
-.081\end{array}$ & $\begin{array}{r}-0.049 \\
-.040\end{array}$ & $\begin{array}{r}+0.059 \\
+.085\end{array}$ & $\begin{array}{r}+0.091 \\
+.127\end{array}$ & $\begin{array}{r}+0.155 \\
+.180\end{array}$ & $\begin{array}{r}+0.015 \\
+.050\end{array}$ & $\begin{array}{r}-0.110 \\
-.071\end{array}$ \\
\hline $\begin{array}{l}\text { Processed: } \\
\text { Crosswise } \\
\text { Lengthwise }\end{array}$ & $\begin{array}{l}-.212 \\
-.186\end{array}$ & $\begin{array}{l}-.159 \\
-.133\end{array}$ & $\begin{array}{l}-.116 \\
-.085\end{array}$ & $\begin{array}{r}+.015 \\
+.045\end{array}$ & $\begin{array}{l}+.070 \\
+.104\end{array}$ & $\begin{array}{l}+.141 \\
+.167\end{array}$ & $\begin{array}{l}-.029 \\
+.014\end{array}$ & $\begin{array}{l}-.163 \\
-.103\end{array}$ \\
\hline
\end{tabular}

REGULAR FILM BASE-Ss. PANCHROMATIC-SAMPLE $B$

\begin{tabular}{|c|c|c|c|c|c|c|c|c|}
\hline $\begin{array}{l}\text { Unprocessed: } \\
\text { Crosswise } \\
\text { Lengthwise }\end{array}$ & $\begin{array}{r}-0.166 \\
-.149\end{array}$ & $\begin{array}{r}-0.111 \\
-.099\end{array}$ & $\begin{array}{r}-0.063 \\
-.046\end{array}$ & $\begin{array}{r}+0.053 \\
+.069\end{array}$ & $\begin{array}{r}+0.082 \\
+.107\end{array}$ & $\begin{array}{r}+0.146 \\
+.160\end{array}$ & $\begin{array}{r}-0.001 \\
+.023\end{array}$ & $\begin{array}{r}-0.133 \\
-.104\end{array}$ \\
\hline Processed: & & & & & & & & \\
\hline $\begin{array}{l}\text { Crosswise } \\
\text { Lengthwise }\end{array}$ & $\begin{array}{l}-.245 \\
-.199\end{array}$ & $\begin{array}{l}-.198 \\
-.152\end{array}$ & $\begin{array}{l}-.144 \\
-.106\end{array}$ & $\begin{array}{l}-.009 \\
+.023\end{array}$ & $\begin{array}{l}+.049 \\
+.070\end{array}$ & $\begin{array}{l}+.114 \\
+.131\end{array}$ & $\begin{array}{l}-.062 \\
-.032\end{array}$ & $\begin{array}{l}-.204 \\
-.168\end{array}$ \\
\hline
\end{tabular}


TABLE 1.-Dimensional change of films in percentages as a function of relative humidity-Continued

\begin{tabular}{l|c|c|c|c|c|c|c|c}
\hline & \multicolumn{7}{|c}{ RELATIVE HUMIDITY } \\
\cline { 2 - 6 } $\begin{array}{c}\text { Treatment and direc- } \\
\text { tion of measurement }\end{array}$ & $32 \%$ & $43 \%$ & $50 \%$ & $65 \%$ & $76 \%$ & $86 \%$ & $65 \%$ & $50 \%$ \\
\hline
\end{tabular}

REGULAR FILM BASE-Ss. PANCHROMATIC-SAMPLE $C$

\begin{tabular}{|c|c|c|c|c|c|c|c|c|}
\hline Unprocessed: & & & & & & & & \\
\hline Crosswise & -0.139 & -0.090 & -0.062 & +0.048 & +0.077 & +0.119 & -0.007 & -0.121 \\
\hline Lengthwise & -.137 & -.086 & -.055 & $\begin{array}{r}+.077 \\
\end{array}$ & +.114 & $\begin{array}{r}0.158 \\
+.15\end{array}$ & +.038 & -.080 \\
\hline $\begin{array}{l}\text { rocessed: } \\
\text { Crosswise }\end{array}$ & -.214 & -.165 & -.125 & +.013 & +.063 & +.112 & -.036 & -.162 \\
\hline Lengthwise & -.206 & -.152 & -.111 & +.041 & +.094 & & -.010 & -.126 \\
\hline Unprocessed: & & & & & & & & \\
\hline Crosswise & -.285 & -.238 & -.184 & -.058 & -.018 & +.040 & -.088 & -.219 \\
\hline Lengthwise & -.276 & -.224 & -.168 & -.056 & -.016 & +.041 & -.078 & -.217 \\
\hline Crosswise & -.409 & -.372 & -.321 & -.193 & -.119 & -.073 & -.213 & -.339 \\
\hline Lengthwise & -.382 & -.344 & -.301 & -.181 & -.115 & -.070 & -.202 & -.318 \\
\hline Oven-treated 14 days: & & & & & & & & \\
\hline Crosswise & -.426 & -.383 & -.335 & -.208 & -.133 & -.088 & -.236 & -.358 \\
\hline Lengthwise & -.382 & -.346 & -.297 & -.176 & -.117 & -.073 & -.212 & -.321 \\
\hline
\end{tabular}

REGULAR FILM BASE-Ss. PANCHROMATIC-SAMPLE $F$

\begin{tabular}{|c|c|c|c|c|c|c|c|c|}
\hline Unprocessed: & & & & & & & & \\
\hline Crosswise & -0.168 & -0.114 & -0.074 & +0.031 & +0.061 & +0.109 & -0.015 & -0.151 \\
\hline $\begin{array}{l}\text { Lengthwise } \\
\text { Oven-treated } 7 \text { days: }\end{array}$ & -.144 & -.092 & -.058 & +.056 & +. 095 & +. 144 & +.023 & -.116 \\
\hline Crosswise................ & -.260 & -.216 & -.184 & -.071 & -.025 & +.035 & -.098 & -.226 \\
\hline Lengthwise.......... & -.217 & -.174 & -.137 & -.041 & -.002 & +.062 & -.062 & -.187 \\
\hline
\end{tabular}

REGULAR FILM BASE-Ss. PANCHROMATIC-SAMPLE $G$

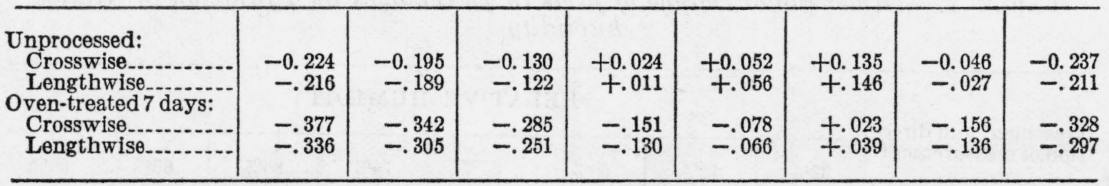

REGULAR FILM BASE-Ss. PANCHROMATIC-SAMPLE $H$

\begin{tabular}{|c|c|c|c|c|c|c|c|c|}
\hline $\begin{array}{l}\text { Unprocessed: } \\
\text { Crosswise } \\
\text { Lengthwise......... }\end{array}$ & $\begin{array}{r}-0154 \\
-.143\end{array}$ & $\begin{array}{r}-0.115 \\
-.103\end{array}$ & $\begin{array}{r}-0.055 \\
-.040\end{array}$ & $\begin{array}{r}+0.044 \\
+.087\end{array}$ & $\begin{array}{r}+0.082 \\
+.140\end{array}$ & $\begin{array}{r}+0.136 \\
+.190\end{array}$ & $\begin{array}{r}+0.005 \\
+.070\end{array}$ & $\begin{array}{r}-0.130 \\
-.067\end{array}$ \\
\hline $\begin{array}{l}\text { Processed: } \\
\text { Crosswise } \\
\text { Lengthwise........ }\end{array}$ & $\begin{array}{l}-.216 \\
-.199\end{array}$ & $\begin{array}{l}-.174 \\
-.160\end{array}$ & $\begin{array}{l}-.112 \\
-.083\end{array}$ & $\begin{array}{r}+.007 \\
+.048\end{array}$ & $\begin{array}{r}+.065 \\
+.114\end{array}$ & $\begin{array}{r}+.132 \\
+.174\end{array}$ & $\begin{array}{r}-.039 \\
+.011\end{array}$ & $\begin{array}{r}-.183 \\
-.130\end{array}$ \\
\hline
\end{tabular}

REGULAR FILM BASE-Ss. PANCHROMATIC-SAMPLE I

\begin{tabular}{|c|c|c|c|c|c|c|c|c|}
\hline $\begin{array}{l}\text { Unprocessed: } \\
\text { Crosswise } \\
\text { Lengthwise }\end{array}$ & $\begin{array}{r}-0.141 \\
-.121\end{array}$ & $\begin{array}{r}-0.103 \\
-.086\end{array}$ & $\begin{array}{r}-0.038 \\
-.023\end{array}$ & $\begin{array}{r}+0.063 \\
+.085\end{array}$ & $\begin{array}{r}+0.121 \\
+.139\end{array}$ & $\begin{array}{r}+0.211 \\
+.221\end{array}$ & $\begin{array}{r}+0.077 \\
+.081\end{array}$ & $\begin{array}{r}-0.054 \\
-.028\end{array}$ \\
\hline $\begin{array}{l}\text { Uven-treated } 7 \text { days: } \\
\text { Crosswise } \\
\text { Lengthwise. }\end{array}$ & $\begin{array}{l}-.192 \\
-.154\end{array}$ & $\begin{array}{l}-.155 \\
-.118\end{array}$ & $\begin{array}{r}-.088 \\
-.068\end{array}$ & $\begin{array}{r}+.012 \\
+.031\end{array}$ & $\begin{array}{r}+.078 \\
+.080\end{array}$ & $\begin{array}{l}+.183 \\
+.176\end{array}$ & $\begin{array}{l}+.025 \\
+.028\end{array}$ & $\begin{array}{l}-.106 \\
-.090\end{array}$ \\
\hline
\end{tabular}

REGULAR FILM BASE-Ss. PANCHROMATIC-SAMPLE $J$

\begin{tabular}{|c|c|c|c|c|c|c|c|c|}
\hline $\begin{array}{l}\text { Unprocessed: } \\
\text { Crosswise }\end{array}$ & $\begin{array}{r}-0.145 \\
-.124\end{array}$ & $\begin{array}{r}-0.106 \\
-.080\end{array}$ & $\begin{array}{r}-0.053 \\
-.030\end{array}$ & $\begin{array}{r}+0.058 \\
+.092\end{array}$ & $\begin{array}{r}+0.115 \\
+.143\end{array}$ & $\begin{array}{r}+0.178 \\
+.201\end{array}$ & $\begin{array}{r}+0.068 \\
+.094\end{array}$ & $\begin{array}{r}-0.058 \\
-.026\end{array}$ \\
\hline $\begin{array}{l}\text { Oven-treated } 7 \text { days: } \\
\text { Crosswise } \\
\text { Lengthwise. }\end{array}$ & $\begin{array}{l}-.202 \\
-.154\end{array}$ & $\begin{array}{l}-.158 \\
-.108\end{array}$ & $\begin{array}{l}-.100 \\
-.060\end{array}$ & $\begin{array}{l}+.012 \\
+.035\end{array}$ & $\begin{array}{l}+.076 \\
+.082\end{array}$ & $\begin{array}{l}+.153 \\
+.150\end{array}$ & $\begin{array}{l}+.020 \\
+.030\end{array}$ & $\begin{array}{l}-.113 \\
-.089\end{array}$ \\
\hline
\end{tabular}


TABLE 1.-Dimensional change of films in percentages as a function of relative humidity-Continued

\begin{tabular}{l|c|c|c|c|c|c|c|c}
\hline & \multicolumn{7}{|c}{ RELATIVE HUMIDITY } \\
$\begin{array}{c}\text { Treatment and direc- } \\
\text { tion of measurement }\end{array}$ & $32 \%$ & $43 \%$ & $50 \%$ & $65 \%$ & $76 \%$ & $86 \%$ & $65 \%$ & $50 \%$ \\
\hline
\end{tabular}

REGULAR FILM BASE-SS. PANCHROMATIC-SAMPLE $K$

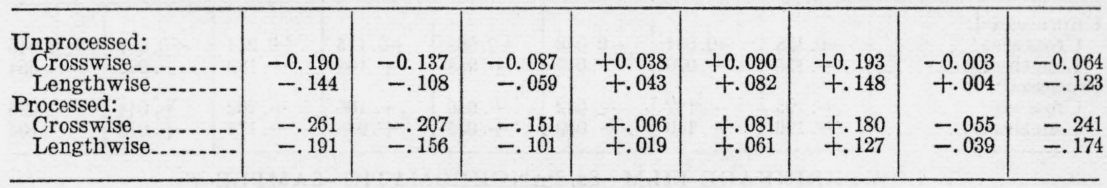

REGULAR FILM BASE-INFRARED SENSITIVE-SAMPLE $N$

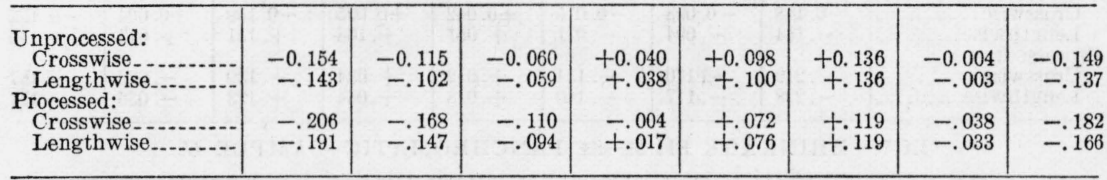

TOPOGRAPHIC FILM BASE-Ss. PANCHROMATIC-SAMPLE $O$

\begin{tabular}{|c|c|c|c|c|c|c|c|c|}
\hline Unprocessed: & & & & & & & & \\
\hline Crosswise & -0.179 & -0.120 & -0.080 & +0.040 & +0.091 & +0.134 & +0.025 & -0.103 \\
\hline $\begin{array}{l}\text { Lengthwise } \\
\text { Oven-treated } 7 \text { days: }\end{array}$ & -.168 & -.113 & -.073 & +. 043 & +.083 & +.138 & +.028 & -.098 \\
\hline Crosswise & -.231 & -.187 & -.147 & -.027 & +.034 & +.099 & -.030 & -.164 \\
\hline Lengthwise.......... & -.221 & -.180 & -.142 & -.042 & +.016 & +.073 & -.045 & -.173 \\
\hline
\end{tabular}

TOPOGRAPHIC FILM BASE-Ss. PANCHROMATIC-SAMPLE $P$

\begin{tabular}{|c|c|c|c|c|c|c|c|c|}
\hline Unprocessed: & & & & & & & & \\
\hline Crosswise & -0.155 & -0.094 & -0.051 & +0.060 & +0.095 & +0.176 & +0.054 & -0.067 \\
\hline $\begin{array}{l}\text { Lengthwise.......... } \\
\text { Processed: }\end{array}$ & -.151 & -.095 & -.048 & +. 086 & +. 130 & +.201 & +.085 & -.048 \\
\hline Crosswise & -.215 & -.151 & -.102 & +.025 & +.085 & +.170 & +.011 & -.121 \\
\hline Lengthwise.......... & -.207 & -.152 & -.088 & +.050 & +.109 & +.183 & +.032 & -.098 \\
\hline
\end{tabular}

TOPOGRAPHIC FILM BASE-Ss. PANCHROMATIC-SAMPLE $Q$

\begin{tabular}{|c|c|c|c|c|c|c|c|c|}
\hline Unprocessed: & & & & & & & & \\
\hline Crosswise & -0.136 & -0.096 & -0.057 & +0.063 & +0.106 & +0.191 & +0.055 & -0.053 \\
\hline Lengthwise & -.134 & -.083 & -.053 & +.077 & +.118 & +.192 & +.064 & -.040 \\
\hline Processed: & & & & & & & & \\
\hline Crosswise & -.194 & -.146 & -.100 & +.045 & +.108 & +.178 & +.023 & $\begin{array}{l}-.095 \\
-.101\end{array}$ \\
\hline Lengthwise.......... & -.205 & -.149 & -.097 & +.046 & +.103 & +.164 & +.017 & -.101 \\
\hline Unprocessed: & & & & & & & & \\
\hline Crosswise & -.225 & -.182 & -.124 & -.004 & +.049 & +.144 & +.007 & -.111 \\
\hline Lengthwise & -.221 & -.174 & -.118 & -.011 & +.033 & +.122 & -.007 & -.126 \\
\hline Oven-treated 7 days: & & & & & & & & \\
\hline Crosswise & -.290 & -.252 & -.194 & -.047 & +.004 & +.065 & -.045 & -.188 \\
\hline Lengthwise & -.295 & -.260 & -.205 & -.079 & -.030 & +.022 & -.081 & -.216 \\
\hline $\begin{array}{l}\text { Oven-treated } 14 \text { days: } \\
\text { Crosswise }\end{array}$ & -.293 & -.261 & -.197 & -.055 & +.005 & +.070 & -.053 & -.190 \\
\hline Lengthwise.............. & -.296 & -.261 & -.211 & -.082 & -.031 & +.017 & -.091 & -.211 \\
\hline
\end{tabular}

TOPOGRAPHIC FILM BASE-SS. PANCHROMATIC-SAMPLE $R$

\begin{tabular}{|c|c|c|c|c|c|c|c|c|}
\hline Unprocessed: & & & & & & & & \\
\hline Crosswise & -0.151 & -0.108 & -0.044 & +0.080 & +0.135 & +0.210 & +0.089 & -0.048 \\
\hline $\begin{array}{l}\text { Lengthwise........... } \\
\text { Processed: }\end{array}$ & -.140 & -.086 & -.045 & +.071 & +.122 & +.190 & +.062 & -.054 \\
\hline Crosswise & -.213 & -.167 & -.093 & +.040 & +.120 & +.194 & +.032 & -.107 \\
\hline Lengthwise & -.200 & -.146 & -.088 & +.045 & +.104 & +.169 & +.020 & -.100 \\
\hline
\end{tabular}


TABLE 1.-Dimensional change of films in percentages as a function of relative humidity-Continued

\begin{tabular}{|c|c|c|c|c|c|c|c|c|}
\hline \multirow{2}{*}{$\begin{array}{l}\text { Treatment and direc- } \\
\text { tion of measurement }\end{array}$} & \multicolumn{8}{|c|}{ RELATIVE HUMIDITY } \\
\hline & $32 \%$ & $43 \%$ & $50 \%$ & $65 \%$ & $76 \%$ & $86 \%$ & $65 \%$ & $50 \%$ \\
\hline
\end{tabular}

TOPOGRAPHIC FILM BASE-FINE-GRAIN PANCHROMATIC-SAMPLE $S$

\begin{tabular}{|c|c|c|c|c|c|c|c|c|}
\hline $\begin{array}{l}\text { Unprocessed: } \\
\text { Crosswise- } \\
\text { Lengthwise }\end{array}$ & $\begin{array}{r}-0.138 \\
-.135\end{array}$ & $\begin{array}{r}-0.094 \\
-.090\end{array}$ & $\begin{array}{r}-0.048 \\
-.049\end{array}$ & $\begin{array}{r}+0.068 \\
+.058\end{array}$ & $\begin{array}{r}+0.115 \\
+.108\end{array}$ & $\begin{array}{r}+0.214 \\
+.189\end{array}$ & $\begin{array}{r}+0.087 \\
+.062\end{array}$ & $\begin{array}{r}-0.045 \\
-.054\end{array}$ \\
\hline Processed: & & & & & & & & \\
\hline $\begin{array}{l}\text { Crosswise } \\
\text { Lengthwise }\end{array}$ & $\begin{array}{l}-.193 \\
-.190\end{array}$ & $\begin{array}{l}-.142 \\
-.140\end{array}$ & $\begin{array}{l}-.082 \\
-.089\end{array}$ & $\begin{array}{l}+.040 \\
+.035\end{array}$ & $\begin{array}{l}+.106 \\
+.088\end{array}$ & $\begin{array}{l}+.202 \\
+.174\end{array}$ & $\begin{array}{l}+.044 \\
+.018\end{array}$ & $\begin{array}{l}-.096 \\
-.103\end{array}$ \\
\hline
\end{tabular}

LOW-SHRINKAGE FILM-Ss. PANCHROMATIC-SAMPLE $T$

\begin{tabular}{|c|c|c|c|c|c|c|c|c|}
\hline $\begin{array}{l}\text { Unprocessed: } \\
\text { Crosswise- } \\
\text { Lengthwise }\end{array}$ & $\begin{array}{r}-0.148 \\
-.144\end{array}$ & $\begin{array}{r}-0.098 \\
-.094\end{array}$ & $\begin{array}{r}-0.075 \\
-.071\end{array}$ & $\begin{array}{r}+0.042 \\
+.051\end{array}$ & $\begin{array}{r}+0.095 \\
+.108\end{array}$ & $\begin{array}{r}+0.159 \\
+.151\end{array}$ & $\begin{array}{r}+0.004 \\
+.013\end{array}$ & $\begin{array}{r}-0.132 \\
-.115\end{array}$ \\
\hline $\begin{array}{l}\text { Processed: } \\
\quad \text { Crosswise } \\
\text { Lengthwise }\end{array}$ & $\begin{array}{l}-.219 \\
-.228\end{array}$ & $\begin{array}{r}-.170 \\
-.177\end{array}$ & $\begin{array}{l}-.134 \\
-.140\end{array}$ & $\begin{array}{l}+.012 \\
+.018\end{array}$ & $\begin{array}{l}+.084 \\
+.084\end{array}$ & $\begin{array}{l}+.130 \\
+.123\end{array}$ & $\begin{array}{l}-.036 \\
-.036\end{array}$ & $\begin{array}{l}-.187 \\
-.177\end{array}$ \\
\hline
\end{tabular}

LOW-SHRINKAGE FILM-Ss. PANCHROMATIC-SAMPLE $U$

\begin{tabular}{|c|c|c|c|c|c|c|c|c|}
\hline $\begin{array}{l}\text { Unprocessed: } \\
\text { Crosswise } \\
\text { Lengthwise }\end{array}$ & $\begin{array}{r}-0.150 \\
-.166\end{array}$ & $\begin{array}{r}-0.097 \\
-.109\end{array}$ & $\begin{array}{r}-0.065 \\
-.077\end{array}$ & $\begin{array}{r}+0.055 \\
+.068\end{array}$ & $\begin{array}{r}+0.093 \\
+.106\end{array}$ & $\begin{array}{r}+0.145 \\
+.158\end{array}$ & $\begin{array}{r}+0.005 \\
+.027\end{array}$ & $\begin{array}{r}-0.124 \\
-.099\end{array}$ \\
\hline $\begin{array}{l}\text { Processed: } \\
\text { Crosswise } \\
\text { Lengthwise }\end{array}$ & $\begin{array}{l}-.226 \\
-.238\end{array}$ & $\begin{array}{l}-.174 \\
-.182\end{array}$ & $\begin{array}{l}-.135 \\
-.134\end{array}$ & $\begin{array}{l}+.011 \\
+.024\end{array}$ & $\begin{array}{l}+.074 \\
+.081\end{array}$ & $\begin{array}{l}+.116 \\
+.127\end{array}$ & $\begin{array}{l}-.046 \\
-.026\end{array}$ & $\begin{array}{l}-.188 \\
-.165\end{array}$ \\
\hline
\end{tabular}

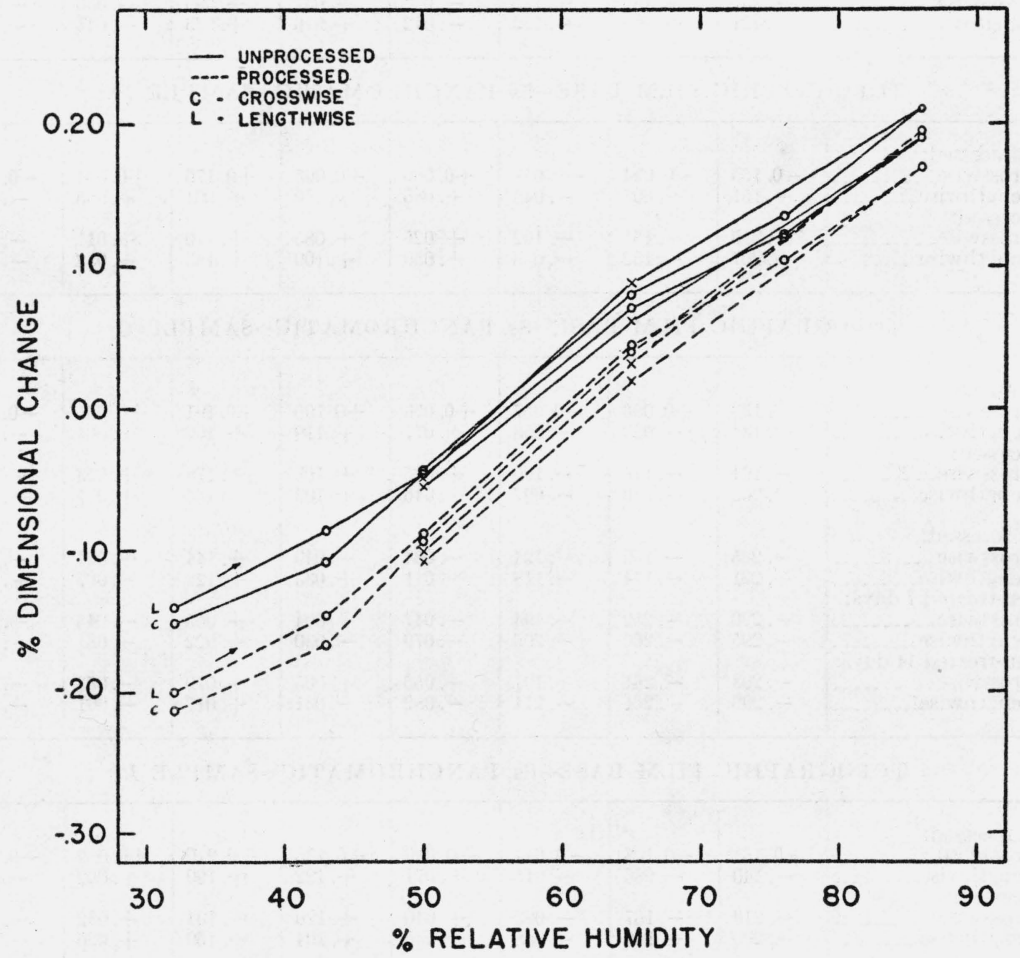

FIGURE 14.-Percentages of shrinkage vs. relative humidity for a regular base infraredsensitive film (sample $N$, table 1 ). 
It was expected that the film should show a hysteresis effect when the humidity was varied - that is, the dimensional changes of the film should lag behind the changes in relative humidity. Ordinarily, a curve showing the relation between cause and effect in a material which exhibits hysteresis is an S curve or a lenticular-shaped curve. The curves of figures 14 to 19 , as a whole, do not properly fit this description. It should be remembered that this series of measurements at different relative humidities was made over a long period of time (about 9 weeks), and that the films were losing some solvent,

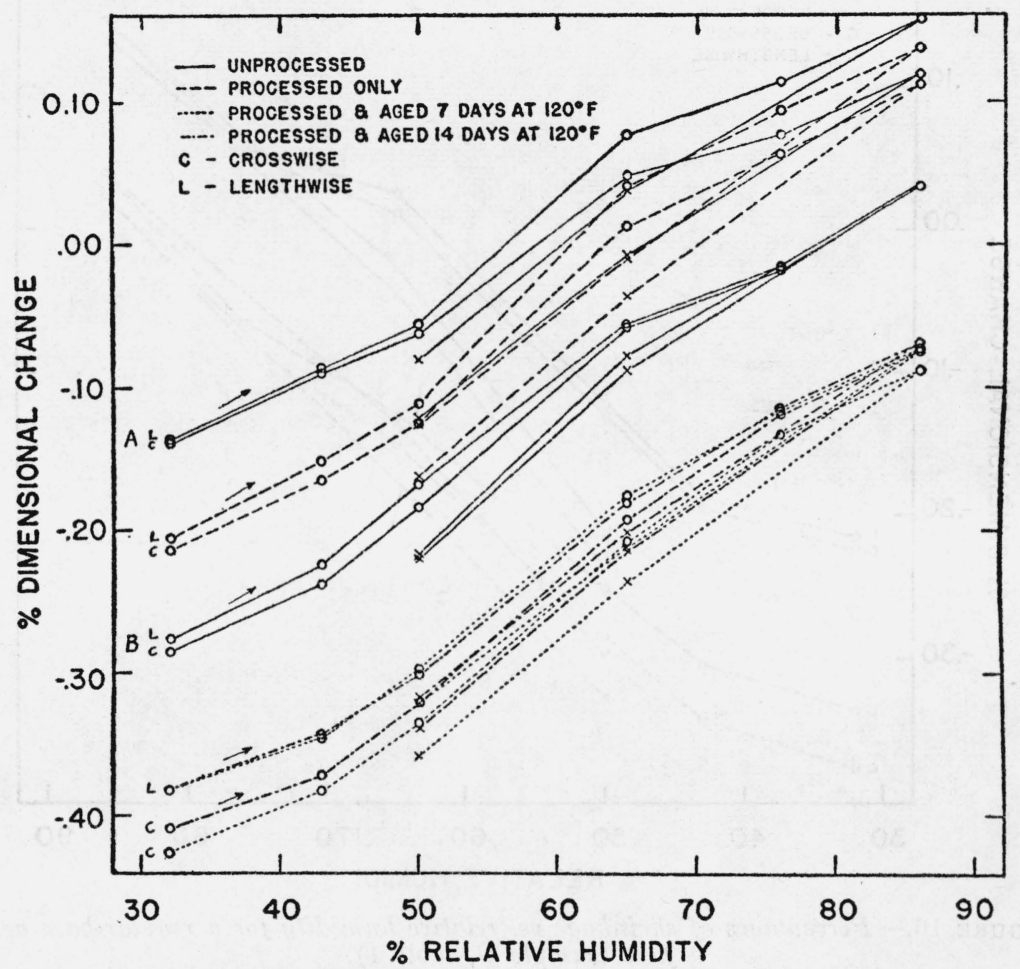

FIGURE 15.-Percentages of shrinkage vs. relative humidity for a regular-base aerofilm (sample C, table 1).

consequently shrinking somewhat all the time. The rate of shrinkage due to this cause is probably not the same at different humidities, and therefore, it would be difficult to make a correction for it. This shrinkage is suggested in that the descending portions of most of the curves shown lie below the ascending portions, instead of above them as in the case of hysteresis curves of paper. With this in mind, it can be seen that certain of the curves, sample $N$, figure 14 , the oventreated test strips of sample $C$, figure 15 , and sample $O$, figure 17 , are S-shaped. 
At 76-percent relative humidity and above, most of the curves seem erratic. In these cases, the observed expansion is too high, probably owing to the gelatin which takes on water more readily than the celluloid and being in contact with the celluloid may have the effect of accelerating the hydration. Hydration and dehydration of the gelatin coating are accompanied by larger expansion and contraction than the celluloid base. This effect is illustrated in figure 20, which shows

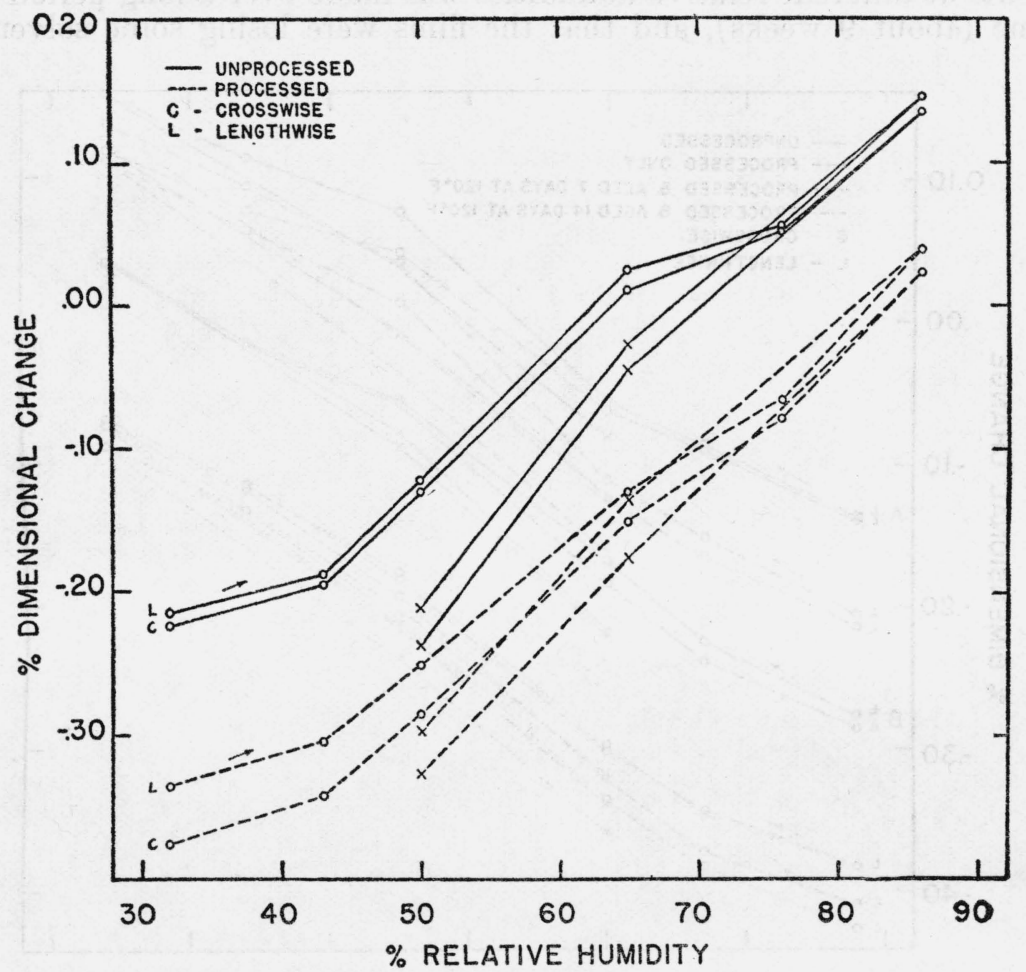

Figure 16.-Percentages of shrinkage vs. relative humidity for a regular-base aerofilm (sample $G$, table 1).

four bottles, each containing two strips of film, one cut lengthwise and the other cut crosswise from the roll. The bottles are closed and each contains a solution to maintain a fixed relative humidity. The relative humidities are, from left to right, $11,37,77$, and 88 percent. The emulsion sides of the films are to the right. It will be noticed that the film cut lengthwise tends to uncurl as the humidity increases. The sample cut crosswise actually bends backward in the 88-percent relative humidity bottle (fig. 20). At about 65- to 70-percent relative humidity films do not curl. 


\section{FILM SHRINKAGE DUE TO PROCESSING AND ACCELERATED AGING}

The effect of processing and of accelerated aging on the dimensions of aerofilm was investigated. Accelerated aging consists in keeping the film in an oven at $120^{\circ} \mathrm{F}\left(49^{\circ} \mathrm{C}\right)$ for 7 days. Two sets of conditions were imposed: One in which the films were conditioned at 50percent relative humidity and $72^{\circ} \mathrm{F}$, and the other in which they were conditioned at 65 -percent relative humidity and $72^{\circ} \mathrm{F}$.

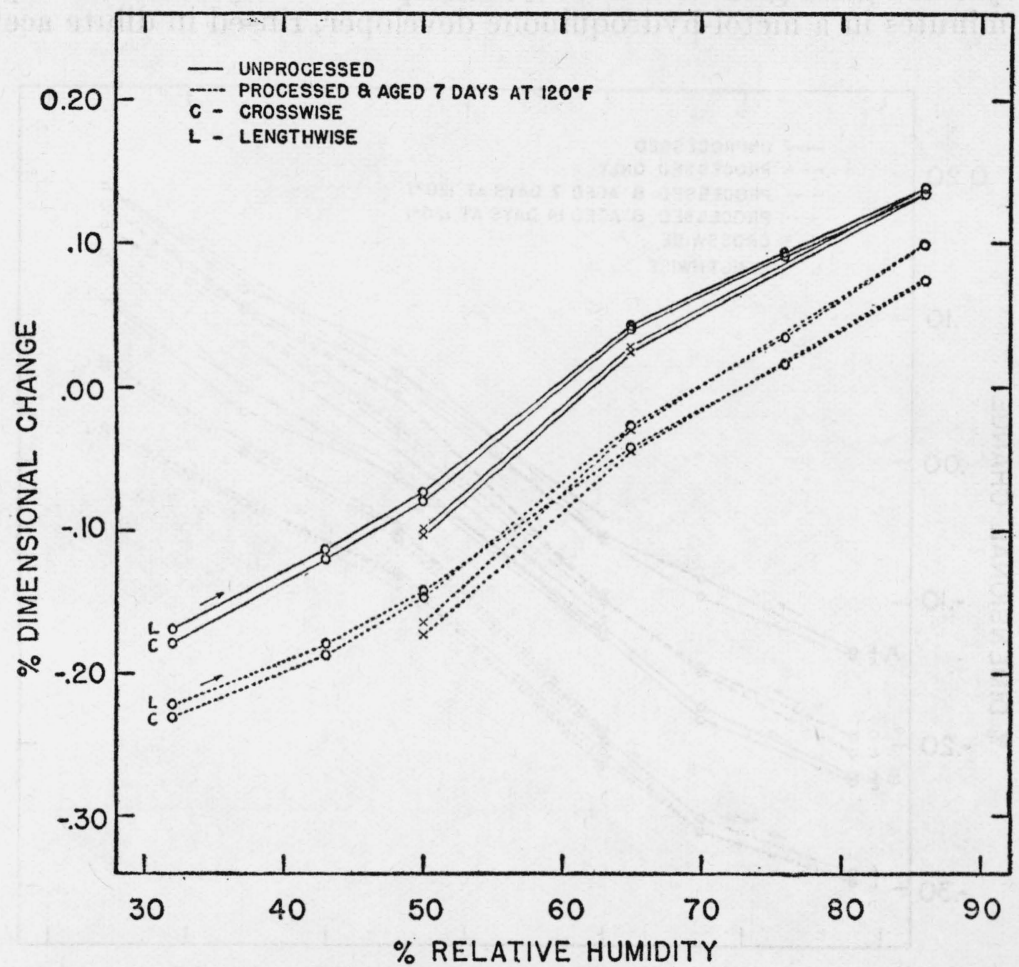

FIGURE 17.-Percentages of shrinkage vs. relative humidity for topographic-base aerofilm (sample 0 , table 1).

For the determinations at 50 -percent relative humidity samples were taken from 21 different rolls of film, each having a different emulsion number, and representing six different types. Test strips were conditioned at 50-percent relative humidity and $72^{\circ} \mathrm{F}$ for 1 or 2 days, measured, processed, reconditioned for 2 days, and remeasured. Then one group of film strips was kept in an oven at $120^{\circ} \mathrm{F}\left(49^{\circ} \mathrm{C}\right)$ for 7 days, reconditioned at 50-percent relative humidity and $72^{\circ} \mathrm{F}\left(49^{\circ} \mathrm{C}\right)$ for 1 to 2 days, and remeasured to determine the shrinkage due to oven treatment (accelerated aging). 
For the shrinkage determinations at 65 -percent relative humidity, 8 by $91 \frac{1}{2}$-inch samples were taken from the same 21 rolls of films, and also 1 sample each from three 8- by 10 -inch cut films. Sample $X$ is chloride emulsion on a cellulose acetate base loaded with some material to make it white and fairly opaque. Its shrinkage is about the same as that of low-shrink base. Two separate determinations were made. The samples were conditioned at 65-percent relative humidity and $72^{\circ} \mathrm{F}$ in a light-tight cabinet with forced ventilation for 64 and 48 hours, respectively, then exposed in contact with a negative of a Max Levy ruled-glass grid with lines $1 / 2$ inch apart. They were developed $2 \frac{114}{4}$ minutes in a metol-hydroquinone developer, rinsed in dilute acetic

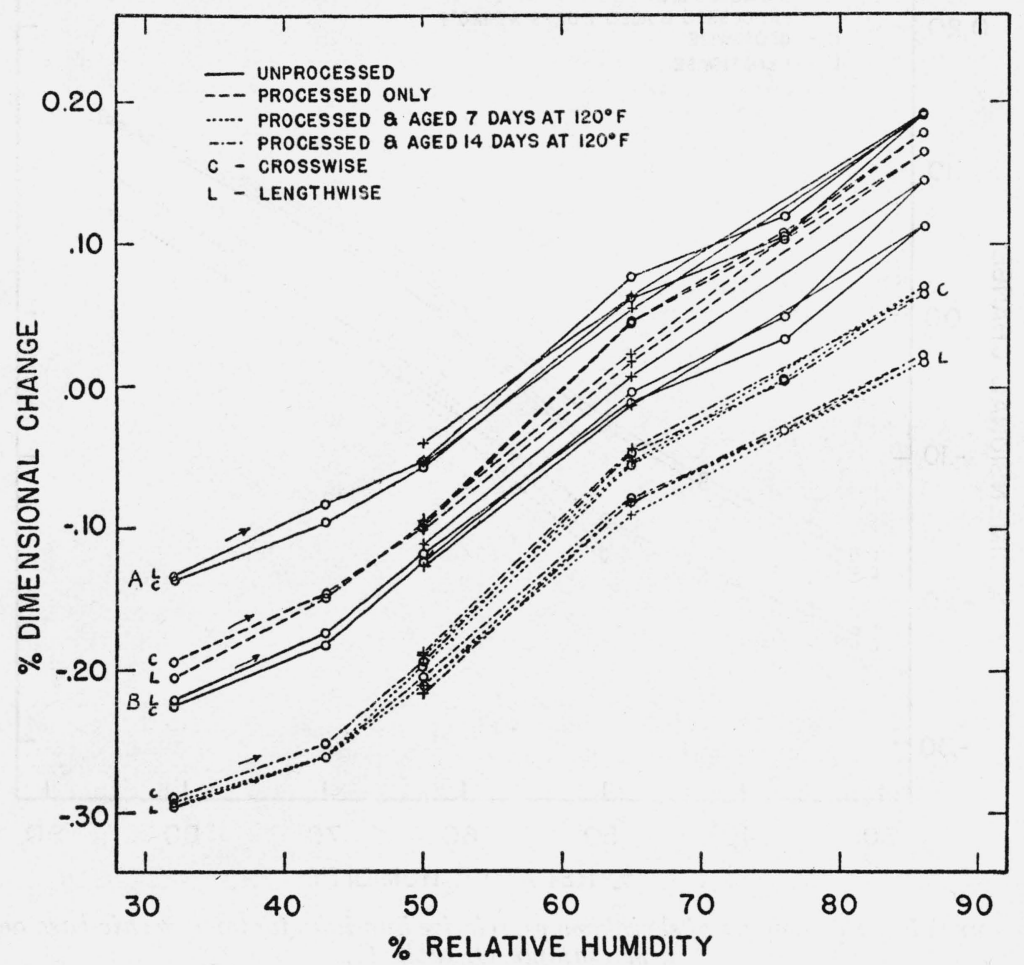

FIGURE 18.-Percentages of shrinkage vs. relative humidity for a topographic-base aerofilm (sample Q, table 1).

acid short-stop bath, fixed 12 minutes, washed $1 / 2$ to 1 hour in running water, and dried in the laboratory. Then they were hung up and conditioned for 21 and 44 hours, respectively, at 65-percent relative humidity and $72^{\circ} \mathrm{F}$, and measured on the optical gage to obtain the dimensional change caused by processing. After being measured they were placed in the oven for 7 days at $120^{\circ} \mathrm{F}\left(49^{\circ} \mathrm{C}\right)$ followed by 2 days reconditioning at 65 -percent relative humidity and $72^{\circ} \mathrm{C}$, and again measured to obtain the dimensional change due to accelerated aging.

The shrinkage of films based upon measurements at 50-percent relative humidity (table 2 ) is much greater than the shrinkage based on measurements at 65 percent (table 3 ). For instance, at 65-percent relative humidity, all the samples of aerofilm would pass Air Corps 
Specification $31004 \mathrm{~B}$ with respect to shrinkage, whereas at 50 percent, eight samples would not have passed this specification. This shows the need of specifying the conditions under which shrinkage is to be measured, if the specifications are to have a definite meaning.

The shrinkage of the aerofilm on special low-shrink base is just as large as that of the topographic aerofilm, both in amount of shrinkage and differential shrinkage. The amount of shrinkage is perhaps a little greater for the special low-shrink base.

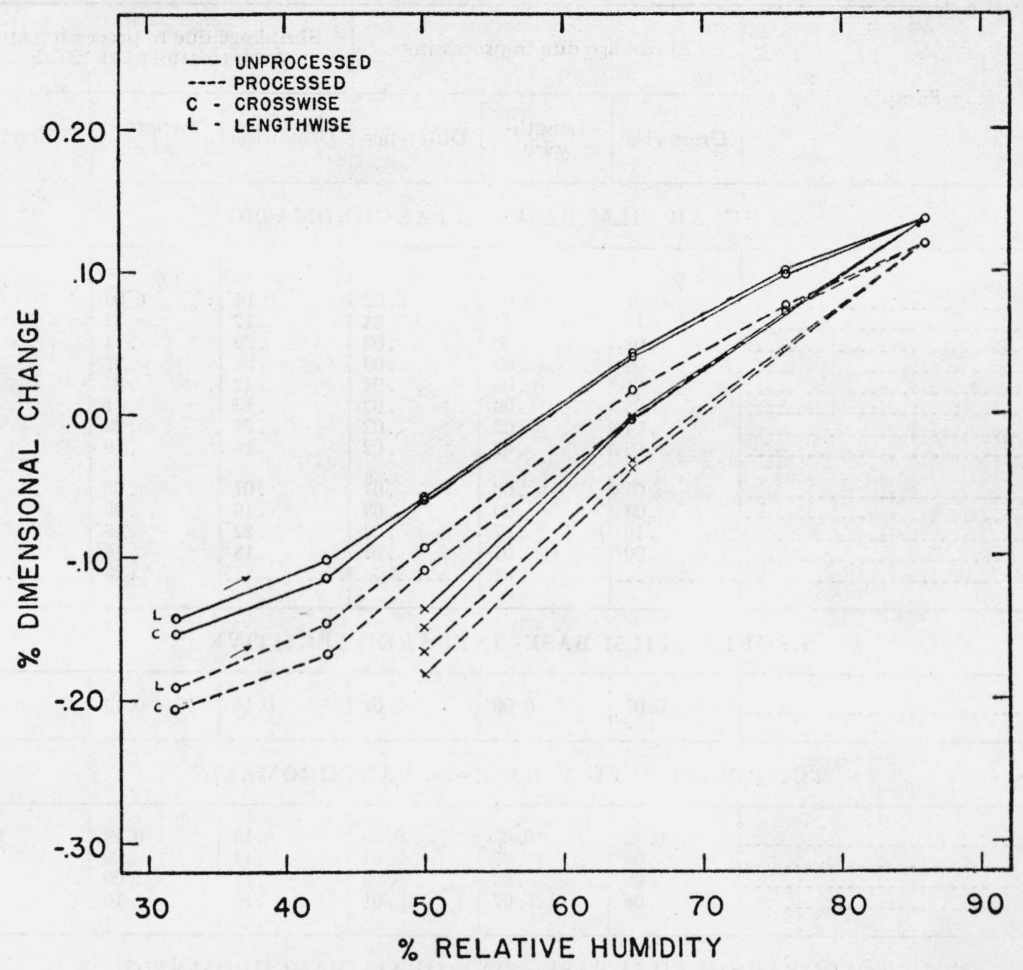

Figure 19.-Percentages of shrinkage vs. relative humidity for a topographic-base aerofilm (sample $R$, table 1 ).

\section{SHRINKAGE OF PHOTOGRAPHIC PAPERS CAUSED BY PROCESSING}

The effect of processing on the dimensions of photographic printing papers was investigated for 32 different samples of contact printing papers and 25 different samples of projection papers. These were in sheets measuring 8 by 10 inches. The paper samples were conditioned in a light-tight conditioning cabinet with forced ventilation, for 24 hours at 65 -percent relative humidity and $72^{\circ} \mathrm{F}$. They were then exposed in contact with the grid. They were processed as follows: Contact papers developed $45 \mathrm{sec}$, projection papers 1.5 minutes, rinsed in acetic acid short-stop bath, fixed about 12 minutes, washed in running water for an hour, surface water blotted off, dried on cheesecloth covered drying racks in uncontrolled atmosphere and returned 
to the conditioning room. After reconditioning for several days at 65 -percent relative humidity and $72^{\circ} \mathrm{F}$ the papers were measured on the optical gage. The distance between lines 6 inches apart was measured at the center, and also about 1 inch from each edge, in both directions, crosswise and lengthwise.

TABLE 2.-Percentage of shrinkage of aeromapping film

[Conditioned at 50-percent relative humidity. Temperature $72^{\circ} \mathrm{F}$.]

\begin{tabular}{|c|c|c|c|c|c|c|}
\hline \multirow{2}{*}{ Sample } & \multicolumn{3}{|c|}{ Shrinkage due to processing } & \multicolumn{3}{|c|}{$\begin{array}{l}\text { Shrinkage due to processing and } \\
\text { oven treatment at } 120^{\circ} \mathrm{F}\end{array}$} \\
\hline & Crosswise & $\begin{array}{l}\text { Length- } \\
\text { wise }\end{array}$ & Difference & Crosswise & $\begin{array}{l}\text { Length- } \\
\text { wise }\end{array}$ & Difference \\
\hline
\end{tabular}

REGULAR FILM BASE-Ss. PANCHROMATIC

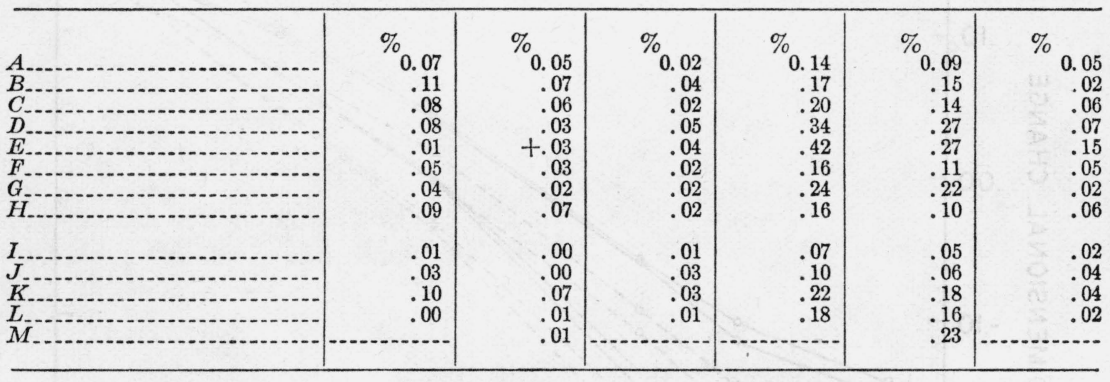

REGULAR FILM BASE-INFRARED SENSITIVE

\begin{tabular}{l|l|l|l|l|l|l|}
\hline$N$ & 0.07 & 0.06 & 0.01 & 0.15 & 0.13 & 0.02 \\
\hline
\end{tabular}

TOPOGRAPHIC FILM BASE-Ss. PANCHROMATIC

\begin{tabular}{|c|c|c|c|c|c|c|}
\hline$P^{O}$ & $\begin{array}{l}0.03 \\
.08 \\
.06 \\
.08\end{array}$ & $\begin{array}{l}0.03 \\
.07 \\
.06 \\
.07\end{array}$ & $\begin{array}{r}0.00 \\
.01 \\
.00 \\
.01\end{array}$ & $\begin{array}{r}0.13 \\
.14 \\
.11 \\
.10\end{array}$ & $\begin{array}{r}0.13 \\
.09 \\
.09 \\
.10\end{array}$ & $\begin{array}{r}0.00 \\
.05 \\
.02 \\
.00\end{array}$ \\
\hline
\end{tabular}

TOPOGRAPHIC FILM BASE-FINE GRAIN PANCHROMATIC

\begin{tabular}{l|l|l|l|l|l|l|}
\hline $5 \ldots \ldots \ldots$ & 0.06 & 0.07 & 0.01 & 0.10 & 0.10 & 0.00 \\
\hline
\end{tabular}

LOW-SHRINKAGE BASE-SS. PANCHROMATIC

\begin{tabular}{r|r|r|r|r|r|r}
\hline$T$ & 0.07 & 0.08 & 0.01 & 0.18 & 0.14 & 0.04 \\
.07 & .08 & .01 & .18 & .03 \\
\hline
\end{tabular}




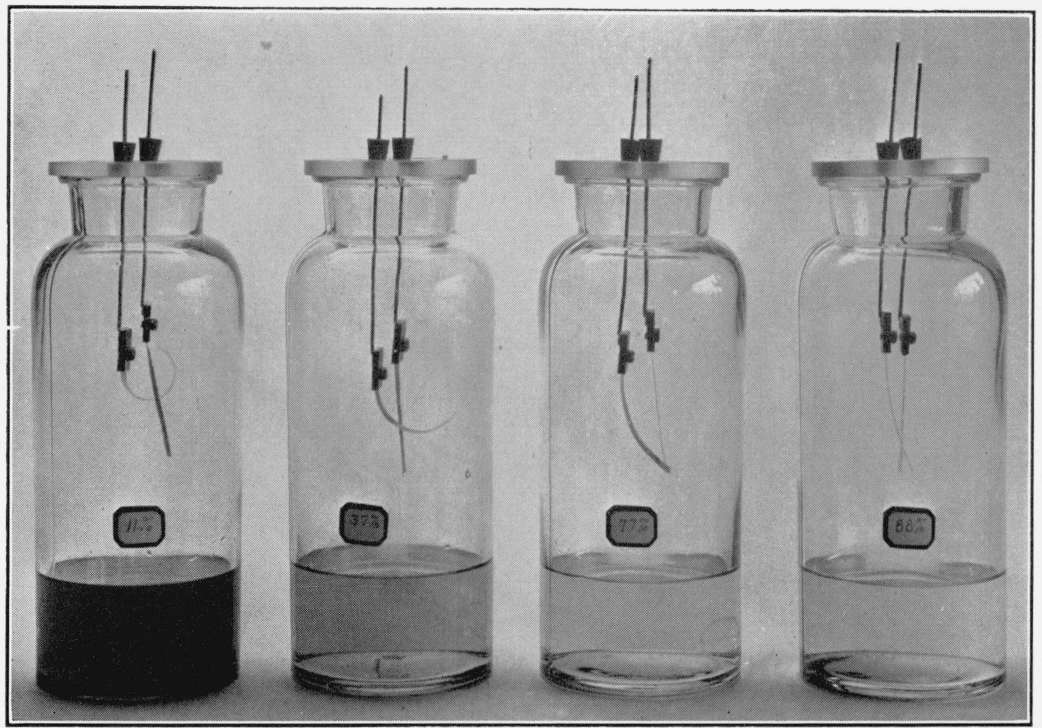

FIGURE 20.-Differences in expansion and contraction of gelatin and celluloid, respectively, with differences in relative humidity.

Gelatin side of films is to the right. Each bottle contains two samples of film, one cut lengthwise and one cut crosswise. From left to right the relative-humidity condition in the bottles is $11,37,77$, and 88 percent, respectively. The sample cut lengthwise uncurls with increasing moisture. 
TABLE 3.-Percentage of shrinkage of aeromapping film

[Conditioned at 65-percent relative humidity. Temperature $72^{\circ} \mathrm{F}$.]

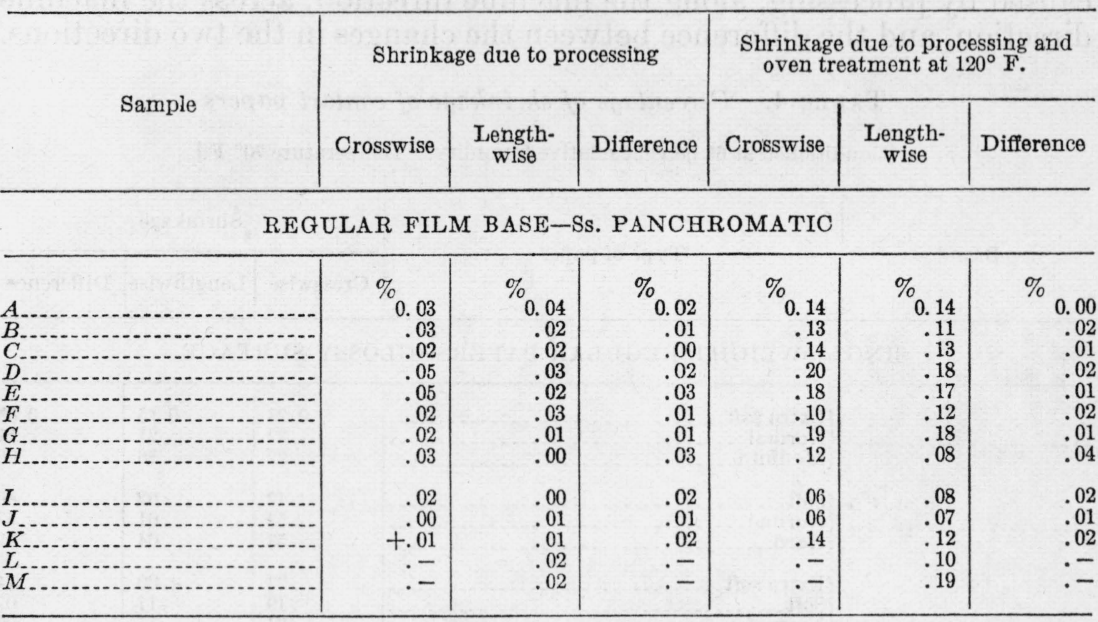

REGULAR FILM BASE-INFRARED SENSITIVE

\begin{tabular}{l|l|l|l|l|l|l|}
\hline$N$ & 0.02 & 0.02 & 0.00 & 0.11 & 0.11 & 0.00 \\
\hline
\end{tabular}

TOPOGRAPHIC FILM BASE-SS. PANCHROMATIC

\begin{tabular}{|c|c|c|c|c|c|c|}
\hline$P_{1}$ & $\begin{array}{l}0.00 \\
.01 \\
.00 \\
.01\end{array}$ & $\begin{array}{l}0.02 \\
.01 \\
.01 \\
.01\end{array}$ & $\begin{array}{r}0.02 \\
.00 \\
.01 \\
.00\end{array}$ & $\begin{array}{r}0.08 \\
.08 \\
.05 \\
.06\end{array}$ & $\begin{array}{r}0.09 \\
.09 \\
.08 \\
.08\end{array}$ & $\begin{array}{r}0.01 \\
.01 \\
.03 \\
.02\end{array}$ \\
\hline
\end{tabular}

TOPOGRAPHIC FILM BASE-FINE GRAIN PANCHROMATIC

\begin{tabular}{|c|c|c|c|c|c|c|}
\hline$S_{1}$ & +0.01 & 0.01 & 0.02 & 0.05 & 0.07 & 0.02 \\
\hline
\end{tabular}

LOW-SHRINKAGE BASE-Ss. PANCHROMATIC

\begin{tabular}{r|r|r|r|r|r|r}
\hline$T$ & 0.00 & 0.02 & 0.02 & 0.10 & 0.11 & 0.01 \\
.02 & .01 & .10 & .01 \\
\hline
\end{tabular}

NITRATE CUT FILM-ORTHOCHROMATIC PRESS

\begin{tabular}{l|l|l|l|l|l|l|}
\hline$V$ & 0.13 & 0.11 & 0.02 & 0.51 & 0.45 & 0.06 \\
\hline
\end{tabular}

SAFETY CUT FILM-ORTHOCHROMATIC PRESS

\begin{tabular}{l|l|l|l|l|l|l}
\hline$W$ & 0.01 & 0.00 & 0.01 & 0.11 & 0.11 & 0.00 \\
\hline
\end{tabular}

EXPERIMENTAL SAFETY CUT FILM

\begin{tabular}{l|l|l|l|l|l|l|}
\hline$X$ & 0.01 & 0.01 & 0.00 & 0.11 & 0.10 & 0.01 \\
\hline
\end{tabular}


The results of the measurements given in tables 4 and 5 were computed and tabulated as percentage dimensional changes of the papers caused by processing, along the machine direction, across the machine direction, and the difference between the changes in the two directions.

TABLE 4.-Percentage of shrinkage of contact papers

[Conditioned at 65 percent relative humidity. Temperature $70^{\circ} \mathrm{F}$.]

\begin{tabular}{|c|c|c|c|c|}
\hline \multirow{2}{*}{ Brand } & \multirow{2}{*}{ Type of paper } & \multicolumn{3}{|c|}{ Shrinkage } \\
\hline & & Crosswise & Lengthwise & Difference \\
\hline \multicolumn{5}{|c|}{ SINGLE-WEIGHT REGULAR PAPERS-GLOSSY SURFACE } \\
\hline$A$ & $\left\{\begin{array}{l}\text { Extra soft-1 } \\
\text { Normal } \\
\text { Medium }\end{array}\right.$ & $\begin{array}{r}0.23 \\
.32 \\
.22\end{array}$ & $\begin{array}{r}0.15 \\
.21 \\
.16\end{array}$ & $\begin{array}{r}0.08 \\
.11 \\
.06\end{array}$ \\
\hline$B \ldots$ & $\left\{\begin{array}{l}\text { Soft_- } \\
\text { Normal- } \\
\text { Hard }\end{array}\right.$ & $\begin{array}{l}.42 \\
.53 \\
.53\end{array}$ & $\begin{array}{l}.02 \\
.01 \\
.04\end{array}$ & $\begin{array}{l}.40 \\
.52 \\
.49\end{array}$ \\
\hline$C_{\ldots}$ & 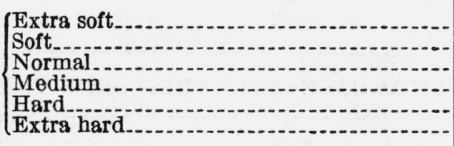 & $\begin{array}{l}.23 \\
.19 \\
.24 \\
.27 \\
.23 \\
.26\end{array}$ & $\begin{array}{l}.09 \\
.17 \\
.15 \\
.25 \\
.11 \\
.20\end{array}$ & $\begin{array}{l}.14 \\
.02 \\
.09 \\
.02 \\
.12 \\
.06\end{array}$ \\
\hline D. & $\left\{\begin{array}{l}\text { Soft_- } \\
\text { Normal } \\
\text { Medium } \\
\text { Hard }\end{array}\right.$ & $\begin{array}{l}.39 \\
.38 \\
.41 \\
.38\end{array}$ & $\begin{array}{l}.23 \\
.26 \\
.29 \\
.25\end{array}$ & $\begin{array}{l}.16 \\
.12 \\
.12 \\
.13\end{array}$ \\
\hline$(a) \ldots$ & (a) & .22 & .21 & .01 \\
\hline
\end{tabular}

SINGLE-WEIGHT REGULAR PAPERS-MATTE SURFACE

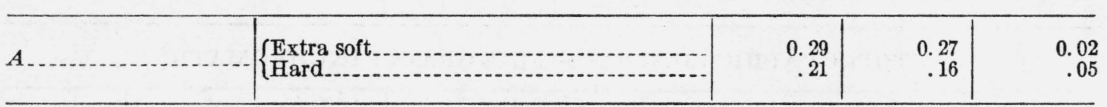

DOUBLE-WEIGHT REGULAR PAPERS-GLOSSY SURFACE

\begin{tabular}{r|r|r|r|r}
\hline & Normal \\
Hard & $\begin{array}{r}0.28 \\
.27\end{array}$ & 0.12 \\
.10 & $\begin{array}{r}0.16 \\
.17\end{array}$ \\
\hline
\end{tabular}

DOUBLE-WEIGHT REGULAR PAPERS-MATTE SURFACE

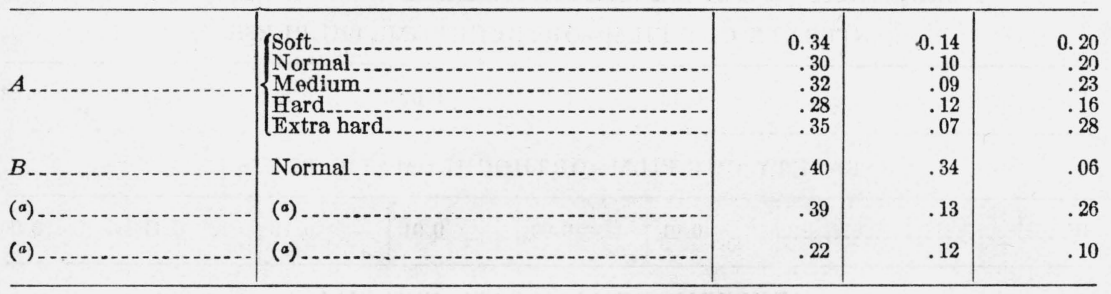

SPECIAL AEROMAPPING PAPERS

\begin{tabular}{|c|c|c|c|c|}
\hline$X$ & Double weight & 0.02 & 0.01 & 0.01 \\
\hline$Y$. & $\left\{\begin{array}{l}\text { Single weight } \\
\text { Double weight. }\end{array}\right.$ & .44 & $\begin{array}{l}.29 \\
.12\end{array}$ & $\begin{array}{l}.15 \\
.01\end{array}$ \\
\hline
\end{tabular}

a Unknown. 
TABLE 5.-Percentage of shrinkage of enlarging papers

[Conditioned at 65 -percent relative humidity. Temperature $70^{\circ} \mathrm{F}$.]

\begin{tabular}{l|c|c|c|}
\hline Brand & Type of paper, contrast and surface & Shrinkage \\
\hline
\end{tabular}

SINGLE-WEIGHT REGULAR PAPERS

\begin{tabular}{|c|c|c|c|c|}
\hline$E^{E}$ & $\begin{array}{l}\text { Medium } \\
\text { Medium semimatte }\end{array}$ & $\begin{array}{r}0.27 \\
.41\end{array}$ & $\begin{array}{r}0.17 \\
.27\end{array}$ & 0.10 \\
\hline$G_{-}$ & $\left\{\begin{array}{l}\text { Medium semimatte } \\
\text { Medium glossy } \\
\text { Medium extra hard }\end{array}\right.$ & $\begin{array}{l}.36 \\
.29 \\
.54\end{array}$ & $\begin{array}{l}.24 \\
.15 \\
.31\end{array}$ & $\begin{array}{l}.12 \\
.14 \\
.23\end{array}$ \\
\hline (s). & Glossy (a). & .30 & .28 & .02 \\
\hline
\end{tabular}

DOUBLE-WEIGHT REGULAR PAPERS

\begin{tabular}{|c|c|c|c|c|}
\hline$H$ & $\left\{\begin{array}{l}\text { Medium matte } \\
\text { Hard matte }\end{array}\right.$ & $\begin{array}{r}0.41 \\
.27\end{array}$ & $\begin{array}{r}0.21 \\
.24\end{array}$ & $\begin{array}{r}0.20 \\
.03\end{array}$ \\
\hline$I$. & Hard & .23 & .09 & .14 \\
\hline$J$ & $\left\{\begin{array}{l}\text { Soft matte } \\
\text { Normal matte- } \\
\text { Medium matte } \\
\text { Hard matte } \\
\text { Extra hard matte }\end{array}\right.$ & $\begin{array}{l}.45 \\
.39 \\
.39 \\
.43 \\
.41\end{array}$ & $\begin{array}{l}.17 \\
.17 \\
.11 \\
.16 \\
.15\end{array}$ & $\begin{array}{l}.28 \\
.22 \\
.28 \\
.27 \\
.26\end{array}$ \\
\hline$K$ & $\left\{\begin{array}{l}\text { Medium semigloss } \\
\text { Hard semigloss }\end{array}\right.$ & $\begin{array}{l}.48 \\
.43\end{array}$ & .13 & .35 \\
\hline L & Hard matte........... & .35 & .08 & .27 \\
\hline$(a)$ & $\left\{\begin{array}{l}\text { Medium matte } \\
\text { White rough matte } \\
\text { White rough matte }\end{array}\right.$ & $\begin{array}{l}.34 \\
.44 \\
.60\end{array}$ & $\begin{array}{l}.33 \\
.13 \\
.14\end{array}$ & $\begin{array}{l}.01 \\
.31 \\
.46\end{array}$ \\
\hline
\end{tabular}

SPECIAL AEROMAPPING PAPERS

\begin{tabular}{|c|c|c|c|c|}
\hline $\mid X_{-1}$ & $\begin{array}{l}\text { Hard matte } \\
\text { Double weight }\end{array}$ & $\begin{array}{r}0.43 \\
.03\end{array}$ & $\begin{array}{r}0.29 \\
.02\end{array}$ & $\begin{array}{r}0.14 \\
.01\end{array}$ \\
\hline$Y$ & $\left\{\begin{array}{l}\text { Single weight } \\
\text { Double weight }\end{array}\right.$ & $\begin{array}{l}44 \\
.18\end{array}$ & $\begin{array}{l}.25 \\
.16\end{array}$ & $\begin{array}{l}.19 \\
.02\end{array}$ \\
\hline
\end{tabular}

METAL LAMINATED PAPER

\begin{tabular}{l|l|l|r|}
\hline$Z \ldots \ldots \ldots$ & Semimatte $\ldots \ldots \ldots \ldots$ & 0.004 \\
\hline
\end{tabular}

- Unknown.

The following papers were found to have very small shrinkage: Brand $Z$, a bromide paper, is a laminated material composed of a sheet of hard aluminum foil cemented between paper. Its shrinkage from processing was less than 0.01 percent. One sample was dried in the oven at $120^{\circ} \mathrm{F}$ for 24 hours and remeasured. It shrank only 0.03 and 0.01 percent, respectively, in two directions at right angles. Brand $X$ is a waterproof paper, made with both contact and enlarging emulsions. The shrinkage of the contact and enlarging papers from processing was 0.02 and 0.03 percent along and 0.01 and 0.02 percent across the sheet, respectively. Their shrinkage caused by 24 hours in the oven at $120^{\circ} \mathrm{F}$ was 0.02 and 0.03 percent along and 0.07 and 0.06 percent across the sheet, respectively. 
The rest of the papers were found to have a maximum shrinkage ranging from about 0.20 to 0.50 percent, four papers having more than 0.50 percent. The differential shrinkage of the papers (i. e., the difference in shrinkage in two directions) ranged from 0.01 to 0.35 percent. Four samples had a differential shrinkage of 0.45 to 0.50 percent. Nine samples had a differential shrinkage of 0.03 percent or less (exclusive of the three papers mentioned above with low maximum shrinkage).

\section{SUMMARY AND RECOMMENDATIONS}

This investigation shows that, under controlled conditions, film shrinkage caused by processing is quite small. Even with 7 days of accelerated aging, the differential shrinkage is, with one exception, under 0.10 percent. A comparison of the data in tables 2 and 3 shows that the shrinkage is noticeably smaller at 65 -percent relative humidity conditioning; in fact, the films which had the highest differential shrinkage at 50 percent show small shrinkage at 65 percent. This indicates that the best results from an accuracy standpoint could be had if all of the work with films is done in a room conditioned at 65-percent relative humidity and $72^{\circ} \mathrm{F}$. A humidity much above 65 percent could not be recommended, because at higher humidities the dimensional behavior of films is erratic.

With photographic papers the results are not so satisfactory. The differential shrinkage is generally above 0.10 percent, but occasionally very low values were obtained without apparent reason, while in other papers of the same brand having different contrast numbers, the shrinkage was much higher. Another inconsistency is that doubleweight papers, as a class, have larger differential shrinkage than singleweight papers. Two of the special aeromapping papers gave very low shrinkage and low differential shrinkage. One of these consists of two pieces of waterproofed paper laminated with a sheet of hard aluminumalloy foil; the other is a cellulose lacquered paper.

The hygroscopic nature of film and paper makes it necessary to adopt, as standard, a fixed condition of temperature and moisture content of the air to which such materials may be subjected at the time of testing. In use, these materials are generally handled under uncontrolled conditions. The shrinkage values given in this paper therefore will not be realized in practice.

Undoubtedly, differential shrinkage in paper can be greatly reduced. Since handmade paper does not have this effect it would seem that paper manufacturers might, after some study, find methods for laying the pulp on the wire so as to prevent lining up the fibers with the machine direction and for reducing the tension to a minimum on the machine. This is an old problem, the cause is known, and the cure should not be too difficult for modern engineers.

We recommend that the machine direction of cut-to-size film and paper be identified by the manufacturer, either on the package or by printing on the back in the case of paper. If this is done, the total differential shrinkage of the combined negative and print or enlargement can be kept at a minimum by having the machine direction of negative and positive material at right angles to each other. 
For example:

Machine direction parallel shrinkage (\%)

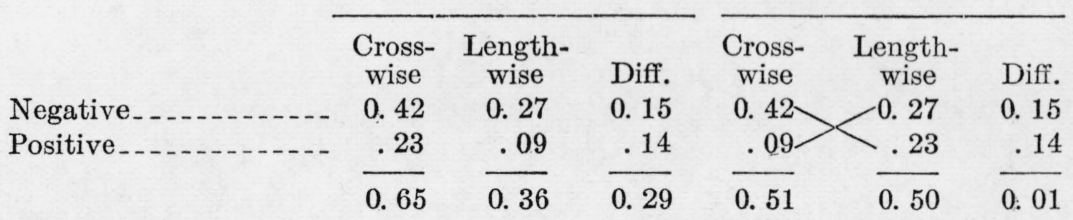

Under the recommended conditions the combined differential shrinkage of the positive and negative material would always be less than the value for the material having the greatest differential shrinkage.

It would appear that only nitrate film is used in aerosurveying. Nitrate film is known to be unstable chemically, decomposing spontaneously with time, so that negatives made on this type of base cannot be classed as permanent. In addition, a large quantity of nitrate film concentrated in one place constitutes a serious fire hazard with the consequent danger to such official records and personnel as may be in the immediate vicinity. The better grades of cellulose acetate base are much more stable chemically than the nitrate base, being in a class with high grade paper with respect to fire hazard and permanence. Acetate film is not used in surveying because it is believed to have inferior shrinkage characteristics. We are unable to find any reliable data on this point and would recommend that a study, similar to that given in this report, be made on acetate film. Considering the lack of permanence and the hazard in storing nitrate film, together with the good behavior of two samples of acetate cut film given in table 3 (last two films), it seems that further attention to this kind of film is warranted.

Washington, October 19, 1937. 